\title{
Y/Hf-doped AICoCrFeNi high-entropy alloy with ultra oxidation and spallation resistance
}

DOI:

10.1016/j.corsci.2019.108426

\section{Document Version}

Accepted author manuscript

Link to publication record in Manchester Research Explorer

\section{Citation for published version (APA):}

Lu, J., Chen, Y., Zhang, H., Ni, N., Li, L., He, L., Mu, R., Zhao, X., \& Guo, F. (2020). Y/Hf-doped AlCoCrFeNi highentropy alloy with ultra oxidation and spallation resistance. Corrosion Science, [108426]. https://doi.org/10.1016/j.corsci.2019.108426

\section{Published in:}

Corrosion Science

\section{Citing this paper}

Please note that where the full-text provided on Manchester Research Explorer is the Author Accepted Manuscript or Proof version this may differ from the final Published version. If citing, it is advised that you check and use the publisher's definitive version.

\section{General rights}

Copyright and moral rights for the publications made accessible in the Research Explorer are retained by the authors and/or other copyright owners and it is a condition of accessing publications that users recognise and abide by the legal requirements associated with these rights.

\section{Takedown policy}

If you believe that this document breaches copyright please refer to the University of Manchester's Takedown Procedures [http://man.ac.uk/04Y6Bo] or contact uml.scholarlycommunications@manchester.ac.uk providing relevant details, so we can investigate your claim.

\section{OPEN ACCESS}




\title{
Y/Hf-doped AlCoCrFeNi High-entropy Alloy with Ultra
}

\section{Oxidation and Spallation Resistance}

\author{
Jie Lu ${ }^{\text {a }}$, Ying Chen ${ }^{\mathrm{b}}$, Han Zhang ${ }^{\mathrm{a}}, \mathrm{Na} \mathrm{Ni}{ }^{\mathrm{c}}, \operatorname{Ling~} \mathrm{Li}^{\mathrm{a}}$, Limin $\mathrm{He}^{\mathrm{d}}$, Rende $\mathrm{Mu}{ }^{\mathrm{d}}$, \\ Xiaofeng Zhao ${ }^{\text {a,* }}$, Fangwei Guo ${ }^{\text {a }}$
}

${ }^{\text {a }}$ Shanghai Key Laboratory of Advanced High-Temperature Materials and Precision Forming, School of Materials Science and Engineering, Shanghai Jiao Tong University, Shanghai, 200240, China

${ }^{\mathrm{b}}$ School of Materials, The University of Manchester, MSS Tower, Manchester M13 9PL, United Kingdom

${ }^{c}$ Key Lab of Education Ministry for Power Machinery and Engineering, School of Mechanical Engineering, Shanghai Jiao Tong University, Shanghai 200240, China

${ }^{\mathrm{d}}$ Beijing Institute of Aeronautical Materials, Beijing, 100095, China

\begin{abstract}
In this study, we report a type of ultra oxidation and spallation resistant Y/Hf-doped AlCoCrFeNi high-entropy alloy (HEA). The alloy exhibits a significantly lower oxidation rate at $1100{ }^{\circ} \mathrm{C}$ with a $\mathrm{k}_{\mathrm{p}}$ value of about $1.9 \times 10^{-13} \mathrm{~g}^{2} \mathrm{~cm}^{-4} \mathrm{~s}^{-1}$, which is one magnitude lower than those of the conventional NiCoCrAlY alloys. Additionally, the alloy shows a strong resistance to the oxide scale spallation. The superior oxidation performance for the Y/Hf-doped HEA can be attributed to the fast establishment of exclusive $\alpha-\mathrm{Al}_{2} \mathrm{O}_{3}$ scale, the beneficial reactive element effect and the large columnar grain size (width) in the oxide scale.
\end{abstract}

Keywords: High-entropy alloy; Oxidation; Spallation; Alumina; High temperature

* Corresponding author: Xiaofeng Zhao (xiaofengzhao@sjitu.edu.cn) 


\section{Introduction}

Metals with exceptional mechanical strength, oxidation and corrosion resistance at high temperatures, have many important engineering applications. However, it has been established that a number of trade-offs must be accepted when it comes to alloy design. For example, Ni-based superalloys with superior creep strength generally do not have sufficient resistance to oxidation required for the long-term durability at high temperatures. To deal with this problem, oxidation resistant coatings are applied to the superalloys during service $[1,2]$. In contrast, FeCrAlY, one of the most oxidation resistant alloys, has relatively low strength at high temperatures, and thus restricts its application as structural components [3-5]. Entropy engineering, however, offers a promising approach to design alloys and overcome the trade-off between high temperature strength and oxidation resistance. As will be demonstrated in this work, the Y/Hf-doped AlCoCrFeNi high-entropy alloy exhibits superior oxidation resistance, which is comparable to those of the most oxidation resistant alloys ever reported, but still maintain high mechanical strength and stability at high temperatures.

High-entropy alloys (HEAs) [6], also referred to as multi-principal element alloys or multi-component alloys [7], have attracted much attention due to their unique compositions, microstructures and adjustable properties [8-11]. The HEAs are originally defined as solution alloys with more than five principal elements in equal or near equal atomic percent (at. \%), which are proposed to be stabilized by the maximized configurational entropy [8-12]. To date, the definition of HEAs has been extended as solution alloys with the composition that the atomic fraction of each principal element is being between 35 and 5 at. \% [8]. Among all HEAs, AlCoCrFeNi exhibits proper yield strength at elevated temperatures and compressive ductility at room temperature, which possibly has the potential for high temperature applications [13-15]. However, it was reported that the oxidation resistance of $\mathrm{AlCoCrFeNi}$ is extremely low. For example, the oxidation products contain spinel or mixed oxides, showing a high oxide growth rate and low spallation resistance $[16,17]$. Butler et.al investigated the oxidation behavior of an equal atomic percent $\mathrm{AlCoCrFeNi} \mathrm{HEA}$ at $1050{ }^{\circ} \mathrm{C}[16,17]$. A large 
amount of non-alumina oxides (e.g. $\left.\mathrm{Cr}_{2} \mathrm{O}_{3}\right)$ formed on the HEA surface and substantial spallation of the oxide scale occurred after $100 \mathrm{~h}$ oxidation. Essentially, the AlCoCrFeNi HEA has similar elemental compositions with those of NiCoCrAlY and FeCrAlY. A good oxidation resistance for this type of alloy is expected to be achieved with the minor doping of reactive elements (REs, e.g. Y or Hf).

It is well accepted that the doping of reactive elements (REs, e.g. Y or Hf) in the typical alumina-forming alloys (e.g. NiCoCrAl, NiAl or FeCrAl alloys) can significantly improve the oxidation performance due to the beneficial REs effects [5, 18-22]. Therefore, in this work, minor concentrations of Y (0.02 at. \%) and $\mathrm{Hf}(0.02$ at. \%) are doped into an AlCoCrFeNi HEA to improve its oxidation performance. It will be demonstrated that the $\mathrm{Y}$ and Hf-doped AlCoCrFeNi HEA exhibits an ultra low oxidation rate, which is about an order of magnitude lower than those of conventional NiCoCrAlY alloys. Extensive characterization of the oxide scale microstructure, growth rate, compositions and spallation lifetime is conducted to understand the mechanisms.

\section{Materials and methods}

\subsection{Sample preparation}

The AlCoCrFeNi alloys were prepared by using equiatomic $\mathrm{Al}, \mathrm{Co}, \mathrm{Cr}, \mathrm{Fe}$, and $\mathrm{Ni}$ metals of high purity ( 99.99 wt. \%) with the addition of reactive elements Y (0.02 at.\%) and $\mathrm{Hf}(0.02$ at.\%) as raw materials and then placed on a water-cooled $\mathrm{Cu}$ hearth under a high-purity argon atmosphere. The alloys were re-melted five times to achieve compositional homogeneity.

\subsection{Isothermal oxidation test}

The AlCoCrFeNiYHf ingot was cut into $10 \times 10 \times 3 \mathrm{~mm}^{3}$ square plates using a $\mathrm{SiC}$ abrasive cutting blade in a precision cut-off machine (Accutom 5, Struers). All the samples were ground with $\mathrm{SiC}$ abrasive papers and polished using $0.05 \mu \mathrm{m}$ 
colloidal alumina following standard metallographic preparation procedure. The samples were thoroughly cleaned with acetone and dried prior to oxidation. All samples for the oxidation experiment were placed in the center of the chamber furnace and near the thermocouple. For the 5 min oxidation, the experiment was conducted in a chamber furnace at $1100{ }^{\circ} \mathrm{C}$ for $5 \mathrm{~min}$ in atmosphere environment, with a rapid heating rate of $200{ }^{\circ} \mathrm{C} / \mathrm{min}$ and fan-assisted air cooling. The isothermal oxidation experiment was performed at $1100{ }^{\circ} \mathrm{C}$ in a chamber furnace at atmosphere environment for different periods of time ranging from $1 \mathrm{~h}$ to $1000 \mathrm{~h}$. The samples were removed from the furnace after the preset exposure time, air-cooled outside the furnace to room temperature for approximately $10 \mathrm{~min}$.

\subsection{Characterization}

The phase composition of the alloy and oxide scale was studied using X-ray diffraction (XRD) in a diffractometer (Ultimo IV, Riau, Japan) fitted with $\mathrm{Cu} \mathrm{K} \alpha$ radiation at 30 $\mathrm{kV}$. The spectra were collected in the $2 \theta$ range of $20 \sim 100^{\circ}$ with a step size of $0.02^{\circ}$ and a scanning speed of $0.5 \% \mathrm{~min}$. The microstructure and chemical composition of samples were examined using scanning electron microscopy (SEM, FEI Nova Nano 230, Netherlands) equipped with energy dispersive X-ray spectroscopy (EDS, Oxford Instruments). To reveal the microstructure of the alloy and oxide scale in greater details, thin lamellae of the alloy and oxide scale were prepared using a focused ion beam (FIB, GAIA3, Tescan, Czech Republic) and analyzed using a scanning transmission electron microscope (STEM, TALOS F200X, FEI, USA) equipped with an EDS system (XIS Ultra DLD, Kratos, Japan). The details of sample preparation can be found elsewhere [23]. Photoluminescence piezospectroscopy (PLPS) was employed to characterize the phase transformation of the thermally grown $\mathrm{Al}_{2} \mathrm{O}_{3}$ in the early oxidation stage using a confocal Raman microprobe (LabRAM HR, Horiba Jobin Yvon, France) fitted with a $532 \mathrm{~nm}$ Nd:YAG laser. The spectra were fitted using mixed Gaussian-Lorentzian functions (Labspec software) to obtain the peak positions. 


\section{Results}

\subsection{The microstructure of as-cast $\mathrm{AlCoCrFeNiYHf} \mathrm{HEA}$}

Fig. 1 shows the morphology of the HEA after etching. As shown in Fig. 1a, dendritic (DR) and interdendritic (ID) regions are uniformly distributed in the equiaxed dendritic grain structure, due to solute segregation during dendritic solidification [25]. In the grains of HEA, a periodic, fine-scale two-phase microstructure can be observed from the DR and ID regions, which can be attributed to the spinodal decomposition mechanism (Fig 1b, c and d) $[25,26]$.
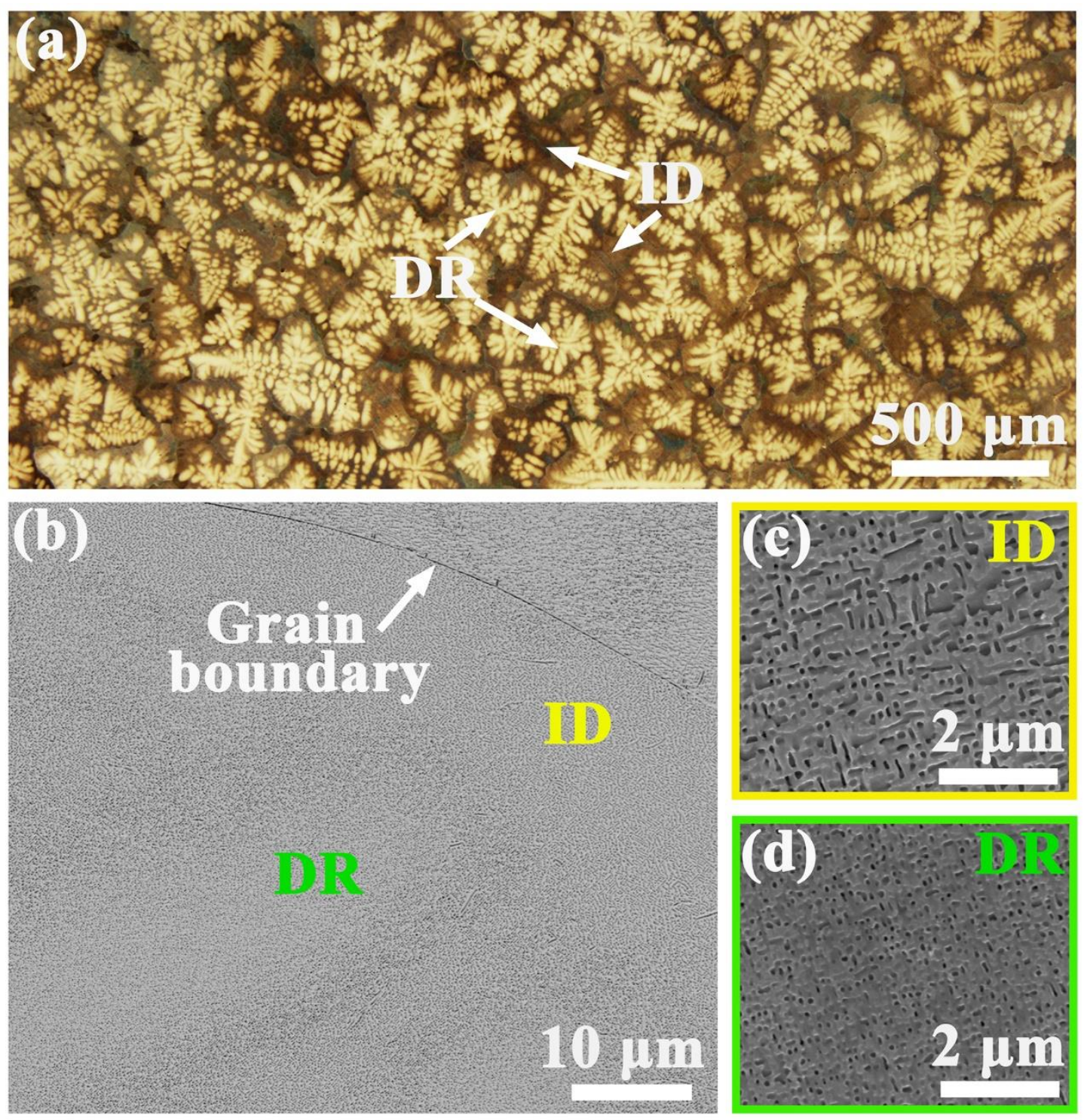

Fig. 1. The morphology of the as-cast AlCoCrFeNiYHf HEA after etching: (a) optical image, giving an overview of the microstructure; (b) backscattered SEM image and (c, 
d) SEM images of ID and DR regions in (b) at a high magnification, respectively. The polished samples were etched using a mixture of $50 \mathrm{vol} . \% \mathrm{HCl}, 50 \mathrm{vol} . \%$ ethanol with 5 wt. $\% \mathrm{CuCl}_{2}$ dissolved [24].

A combination of HAADF-STEM (Fig.2a and b) and SAED analysis (Fig.2c and d) confirms that the ID and DR regions comprise of an ordered BCC (B2) matrix (dark contrast) and disordered BCC (A2) precipitates (bright contrast) [14, 25]. The average width of the A2 and B2 phases, determined by quantitative image analysis, are $\sim 103$ $\mathrm{nm}$ and $\sim 56 \mathrm{~nm}$, respectively, in the ID regions and $81 \mathrm{~nm}$ and $\sim 58 \mathrm{~nm}$, respectively, in the $\mathrm{DR}$ regions. EDS maps indicate that $\mathrm{Al}$ and $\mathrm{Ni}$ are enriched in the $\mathrm{B} 2$ phases and $\mathrm{Fe}$ and $\mathrm{Cr}$ preferentially segregate in the A2 phases, while Co is uniformly distributed. The compositions of the $\mathrm{A} 2$ and $\mathrm{B} 2$ phases in the ID and DR regions are summarized in Table 1.
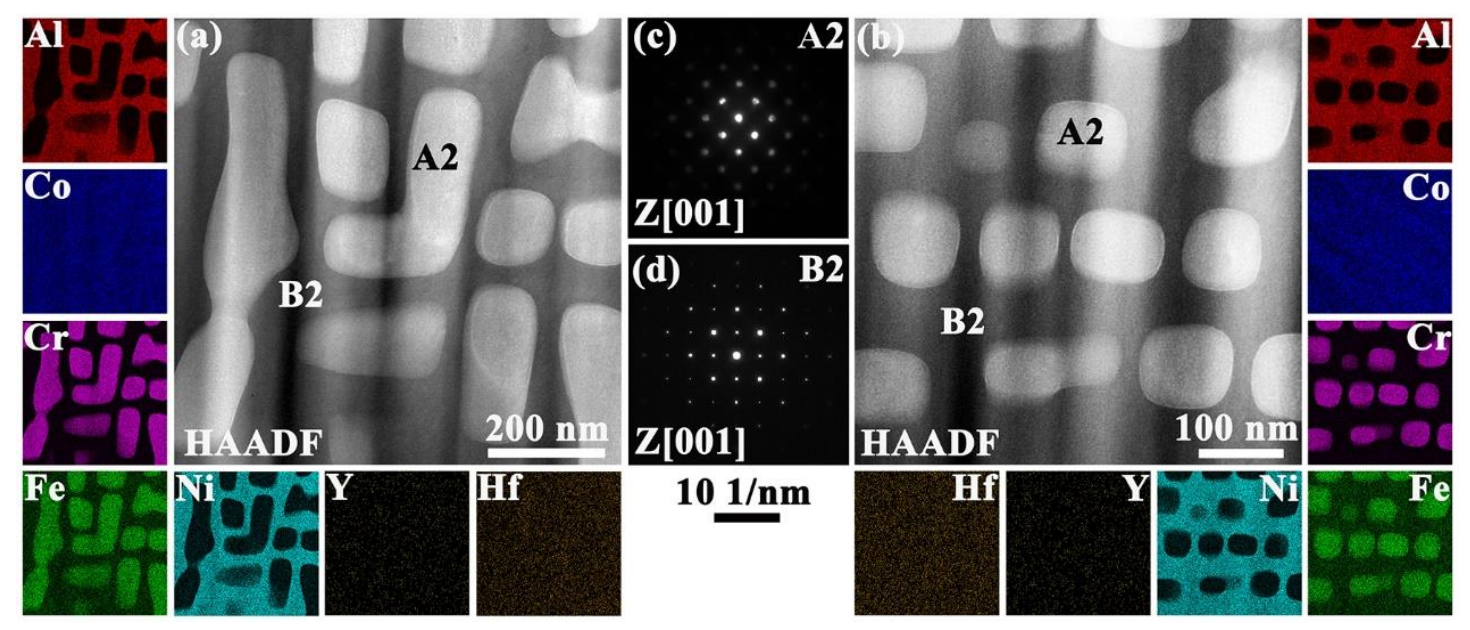

Fig. 2. TEM analysis of the as-cast AlCoCrFeNiYHf HEA: (a) high-angle annular darkfield (HAADF) STEM image of an ID region with corresponding X-ray maps; (b) HAADF STEM image of an DR region with corresponding X-ray maps; (c, d) selectedarea diffraction (SAED) patterns of A2 and B2 phases ([001] zone axis), showing typical disordered body-centered cubic (BCC) and ordered BCC structure, respectively. 
Table 1. Chemical compositions (at. \%) of the A2 and B2 phases in the ID and DR regions determined by STEM-EDS point analysis

\begin{tabular}{cllllll}
\hline \multirow{2}{*}{ HEA } & \multirow{2}{*}{ Phases } & \multicolumn{5}{l}{ Element (at. \%) } \\
\cline { 3 - 7 } & & \multicolumn{1}{c}{$\mathrm{Al}$} & \multicolumn{1}{c}{$\mathrm{Co}$} & $\mathrm{Cr}$ & $\mathrm{Fe}$ & \multicolumn{1}{c}{$\mathrm{Ni}$} \\
\hline \multirow{2}{*}{ ID } & $\mathrm{A} 2$ & $3.8 \pm 0.6$ & $19.8 \pm 2.9$ & $41.3 \pm 4.5$ & $28.1 \pm 3.6$ & $7.0 \pm 1.5$ \\
& $\mathrm{~B} 2$ & $30.7 \pm 2.2$ & $21.3 \pm 3.4$ & $3.6 \pm 1.0$ & $12.9 \pm 2.3$ & $31.5 \pm 4.6$ \\
\multirow{2}{*}{ DR } & $\mathrm{A} 2$ & $3.9 \pm 0.5$ & $18.7 \pm 2.6$ & $43.1 \pm 4.5$ & $27.6 \pm 3.3$ & $6.7 \pm 1.3$ \\
& $\mathrm{~B} 2$ & $30.6 \pm 2.8$ & $22.2 \pm 4.6$ & $4.0 \pm 1.6$ & $12.1 \pm 2.5$ & $31.1 \pm 4.9$ \\
\hline
\end{tabular}

\subsection{The microstructure of oxide scale formed on the AlCoCrFeNiYHf HEA}

For the typical alumina-forming alloys (e.g. NiCoCrAlY and NiAlHf), the formation of protective $\alpha-\mathrm{Al}_{2} \mathrm{O}_{3}$ is often accompanied by nucleation and growth of $\theta-\mathrm{Al}_{2} \mathrm{O}_{3}$ in the initial oxidation stage above $1000{ }^{\circ} \mathrm{C}[19,24,27-30]$. The $\theta-\mathrm{Al}_{2} \mathrm{O}_{3}$ is less protective, and undergoes a progressive $\theta$ to $\alpha-\mathrm{Al}_{2} \mathrm{O}_{3}$ phase transformation during the subsequent oxidation. The lower phase transformation rate of $\theta$ to $\alpha-\mathrm{Al}_{2} \mathrm{O}_{3}$ leads to the higher oxidation rate in the early oxidation stage due to the faster growth of $\theta-\mathrm{Al}_{2} \mathrm{O}_{3}$ than $\alpha$ $\mathrm{Al}_{2} \mathrm{O}_{3}$ [29]. Fig. 3 shows the surface morphology of oxide scale on the HEA after 5 min oxidation. As shown in Fig. 3a and b, the $\mathrm{Al}_{2} \mathrm{O}_{3}$ scale shows a uniform morphology after 5 min oxidation. PLPS spectra of the $\mathrm{Al}_{2} \mathrm{O}_{3}$ scale only show single characteristic $\alpha-\mathrm{Al}_{2} \mathrm{O}_{3}$ doublet, irrespective of the areas being probed. This suggests that the $\mathrm{Al}_{2} \mathrm{O}_{3}$ scale on the HEA only contains $\alpha-\mathrm{Al}_{2} \mathrm{O}_{3}$ after 5 min oxidation. 


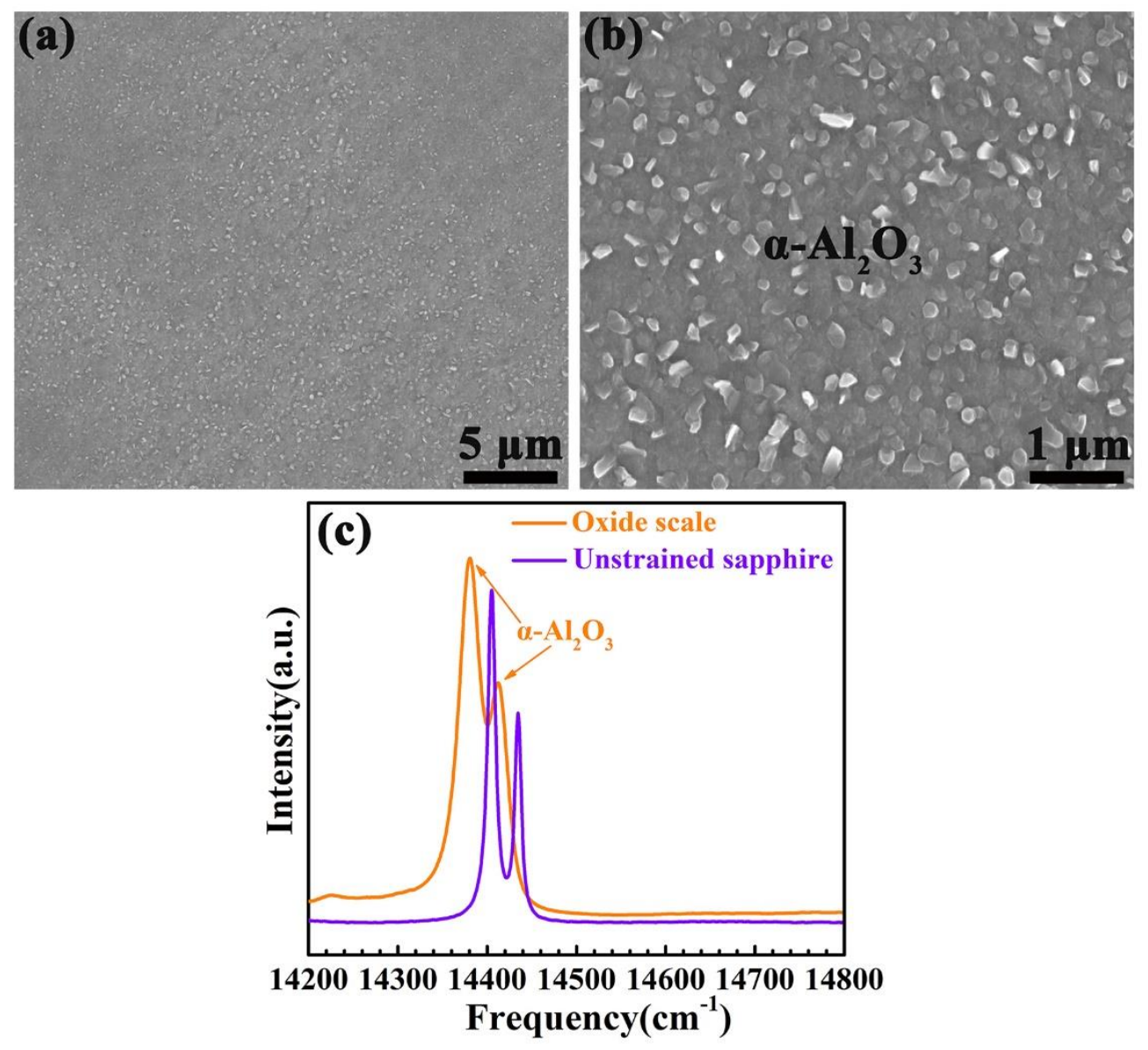

Fig. 3. (a, b) surface morphology of the AlCoCrFeNiYHf HEA after isothermal oxidation at $1100{ }^{\circ} \mathrm{C}$ for $5 \mathrm{~min}$; (c) PLPS spectra of the thermally grown $\mathrm{Al}_{2} \mathrm{O}_{3}$ scale and a stress-free sapphire crystal. Only $\alpha-\mathrm{Al}_{2} \mathrm{O}_{3}$ is identified in the $\mathrm{Al}_{2} \mathrm{O}_{3}$ scale.

Fig. 4 shows the surface morphology of the oxide scale formed on the HEA as a function of oxidation time. As presented in Fig. 4a, d and g, the oxide scale is well adherent with the HEA substrate with the increased oxidation time. No spallation of the oxide scale can be observed even up to $1000 \mathrm{~h}$ oxidation at $1100{ }^{\circ} \mathrm{C}$. This indicates that the AlCoCrFeNiYHf HEA has superior resistance to spallation of the oxide scale, which significantly outperforms conventional MCrAlY alloys under the same oxidation conditions $[24,31]$. The high magnification BSE images in Fig.4 clearly show that the $\alpha-\mathrm{Al}_{2} \mathrm{O}_{3}$ grains uniformly develop on the surface of the AlCoCrFeNiYHf HEA. The bright phases in the oxide scale are Y/Hf-rich oxides, predominately sitting on the triple junctions of the $\alpha-\mathrm{Al}_{2} \mathrm{O}_{3}$ grain boundaries. The presence of the $\mathrm{Y} / \mathrm{Hf}$-rich oxides at the $\alpha-\mathrm{Al}_{2} \mathrm{O}_{3}$ grain boundaries is expected, which results from the low solubility of $\mathrm{Y} / \mathrm{Hf}[21$, 32]. 


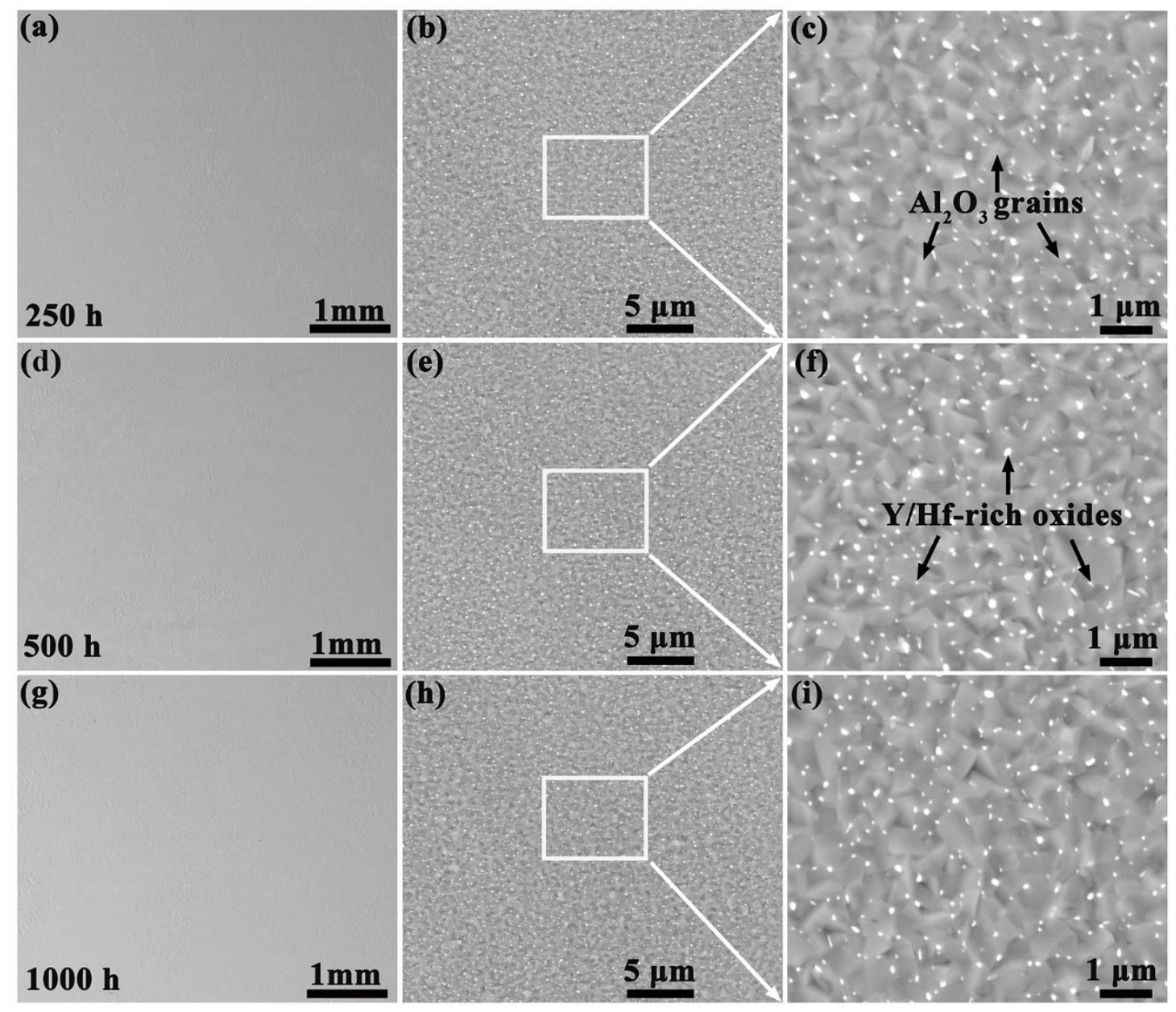

Fig. 4. Surface morphology of the oxide scale formed on the AlCoCrFeNiYHf HEA after isothermal oxidation at $1100{ }^{\circ} \mathrm{C}$ for (a-c) $250 \mathrm{~h}$, (d-e) $500 \mathrm{~h}$ and (g-i) $1000 \mathrm{~h}$. The images for a given oxidation time are presented with incremental magnifications to give both the overview and grain structure of the oxide scale.

The phase constitutions of the oxide scale formed on the AlCoCrFeNiYHf HEA substrate are studied by XRD, which is presented in Fig. 5. The $\alpha-\mathrm{Al}_{2} \mathrm{O}_{3}$ is the predominant phase in the oxide scale after oxidation for $250 \mathrm{~h}, 500 \mathrm{~h}$ and $1000 \mathrm{~h}$. Apart from $\alpha-\mathrm{Al}_{2} \mathrm{O}_{3}, \mathrm{HfO}_{2}$ and $\mathrm{Y}_{3} \mathrm{Al}_{5} \mathrm{O}_{12}$ are also identified in the oxide scale, which is in agreement with the observations in Fig.4 showing the presence of the Y/Hf-rich oxides at the $\alpha-\mathrm{Al}_{2} \mathrm{O}_{3}$ grain boundary triple junctions. 


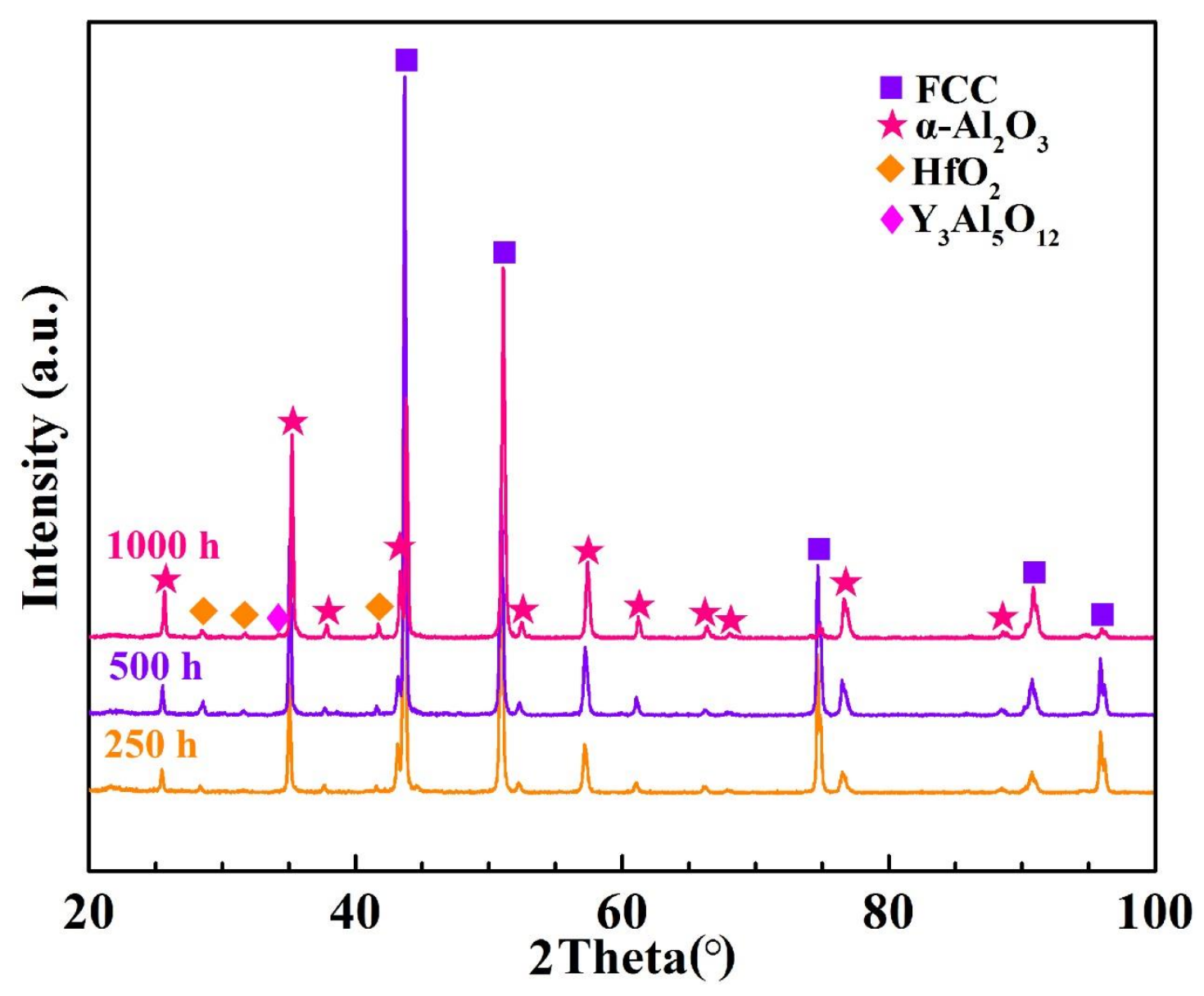

Fig. 5. XRD results of the AlCoCrFeNiYHf HEA after isothermal oxidation at $1100{ }^{\circ} \mathrm{C}$ for $250 \mathrm{~h}, 500 \mathrm{~h}$, and $1000 \mathrm{~h}$.

Fig. 6 shows the cross-sectional microstructure of the oxide scale and the underlying AlCoCrFeNiYHf HEA substrate after $250 \mathrm{~h}$ oxidation. A uniform and continuous oxide scale develops on the HEA and the oxide scale/substrate interface is smooth and clean (Fig.6a). The oxide scale predominantly consists of $\alpha-\mathrm{Al}_{2} \mathrm{O}_{3}$ and minor quantity of $\mathrm{Y}$ /Hf-rich oxides. The incorporation of $\mathrm{Y} / \mathrm{Hf}$-rich oxides into the $\alpha-\mathrm{Al}_{2} \mathrm{O}_{3}$ scale can be attributed to the high oxygen affinity of reactive elements [33]. Additionally, Y/Hf enriched precipitates can be also observed in the HEA substrate due to the low solubility of these two reactive elements in the HEA [34]. 


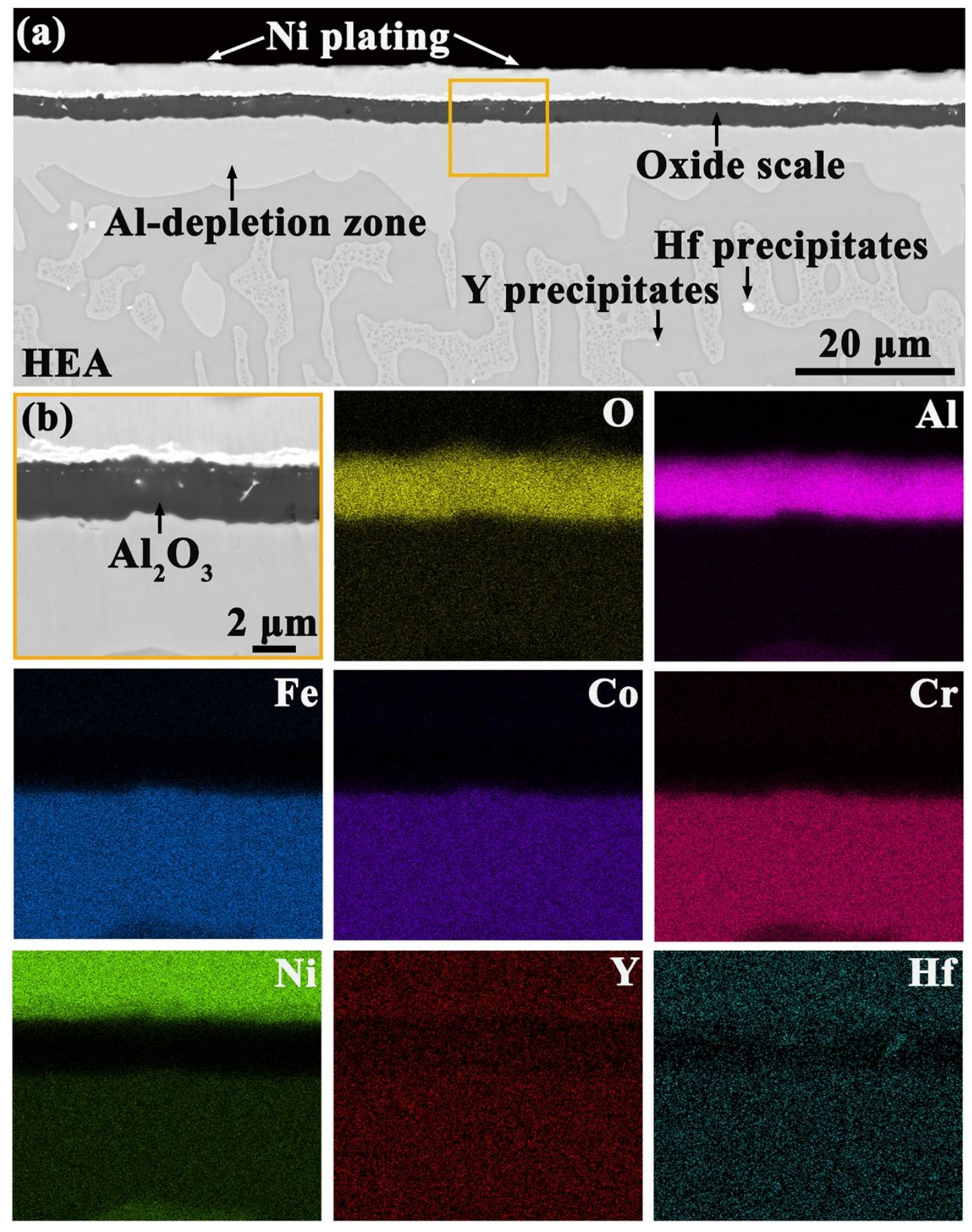

Fig. 6. Cross-sectional microstructure of the AlCoCrFeNiYHf HEA after isothermal oxidation at $1100{ }^{\circ} \mathrm{C}$ for $250 \mathrm{~h}$ : (a) a low magnification backscattered SEM image, giving an overview of the oxide scale and HEA substrate; (b) a high magnification backscattered SEM image over the area within the yellow rectangle in (a) and corresponding X-ray maps.

TEM analysis shows that the oxide scale comprises of an equiaxed outer layer and a 
columnar inner layer (Fig. 7). The duplex structure of the oxide scale derives from the concurrent inward oxygen diffusion and outward aluminum diffusion, which is commonly found in the oxide scales formed on the RE-doped NiCoCrAl, NiAl, and FeCrAl alloys $[18,19,24,35]$. The $\alpha-\mathrm{Al}_{2} \mathrm{O}_{3}$-based oxide scale with minor amount of Hf-rich oxides can be also observed, which is consistent to the observations in Fig. 6b.

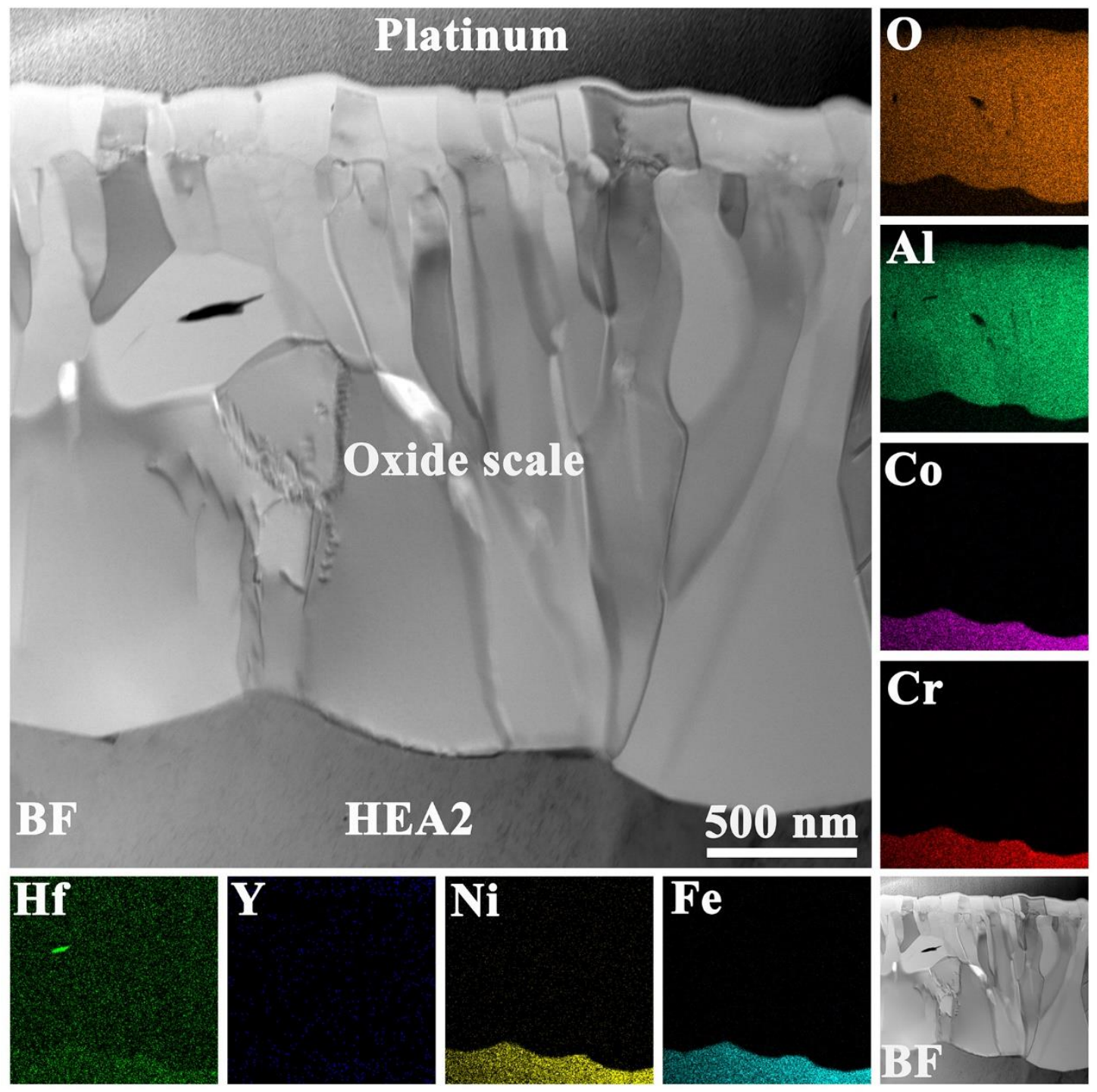

Fig. 7. TEM analysis of the oxide scale formed on the AlCoCrFeNiYHf HEA after isothermal oxidation at $1100{ }^{\circ} \mathrm{C}$ for $250 \mathrm{~h}$, showing the composition and microstructure of oxide scale grains in combination with X-ray maps.

Fig. 8 shows the evolution of the cross-sectional microstructure of the oxide scale as a function of oxidation time. The oxide scale thickness is uniform and reaches $2.6 \pm 0.2$ $\mu \mathrm{m}$ after $250 \mathrm{~h}$ oxidation (Fig. 8a and b). The oxide scale thickens to $3.7 \pm 0.2 \mu \mathrm{m}$ after 
$500 \mathrm{~h}$ oxidation. Nychka and Clarke [18] have reported that the average oxide scale thickness for Y-doped and $\mathrm{Y}_{2} \mathrm{O}_{3}$-doped $\mathrm{FeCrAl}$ alloys after $124 \mathrm{~h}$ oxidation at $1100{ }^{\circ} \mathrm{C}$ are $3.7 \mu \mathrm{m}$ and $4.3 \mu \mathrm{m}$, respectively, which is higher than the oxide scale thickness of the AlCoCrFeNiYHf HEA after $500 \mathrm{~h}$ oxidation. Sloof et al. [34] have also reported that the average scale thickness from the areas without the occurrence of RE-rich oxide inclusions exceeds $6 \mu \mathrm{m}$ for a free-standing NiCoCrAlY alloy deposited by electron beam physical vapor deposition (EB-PVD) after $750 \mathrm{~h}$ oxidation at $1100{ }^{\circ} \mathrm{C}$. Our previous study has also indicated that the $\alpha-\mathrm{Al}_{2} \mathrm{O}_{3}$ scale thickness is above $6 \mu \mathrm{m}$ for a novel, oxidation resistant NiCoCrAlY alloy fabricated via powder milling and spark plasma sintering (SPS) after $480 \mathrm{~h}$ oxidation at $1100{ }^{\circ} \mathrm{C}$ [24]. However, the oxide scale thickness on the AlCoCrFeNiYHf HEA used in the study is merely $4.6 \pm 0.3 \mu \mathrm{m}$ and meanwhile no microstructural defects (e.g. pores and oxide intrusions) are detected at the oxide scale/substrate interface after $1000 \mathrm{~h}$ oxidation. The absence of oxide intrusions is possibly due to low levels of Y and Hf chosen. These results clearly indicate that the AlCoCrFeNiYHf HEA shows superior oxidation resistance and strong oxide/substrate interface adhesion. 


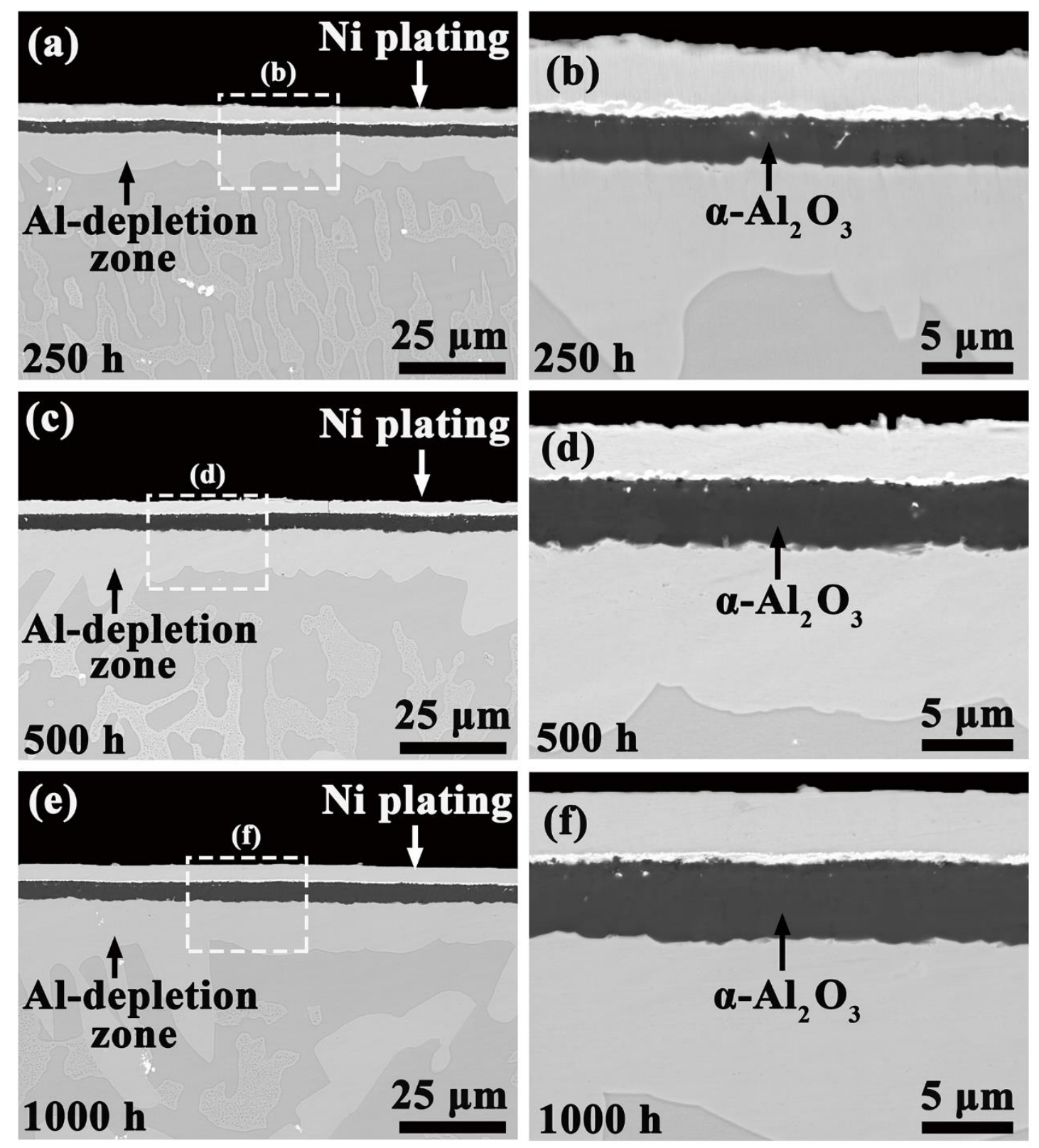

Fig. 8. Cross-sectional microstructure of the AlCoCrFeNiYHf HEA after isothermal oxidation at $1100{ }^{\circ} \mathrm{C}$ for $(\mathrm{a}, \mathrm{b}) 250 \mathrm{~h},(\mathrm{c}, \mathrm{d}) 500 \mathrm{~h}$ and (e, f) $1000 \mathrm{~h}$. The backscattered SEM images in Fig.8a, c and e give an overview of the oxide scales and the substrates. The high magnification backscattered SEM images in Fig. $8 \mathrm{~b}, \mathrm{~d}$ and $\mathrm{f}$ show in details the morphology of the oxide scales and the substrates within the white rectangles in Fig.8a, c and e, respectively. 


\subsection{Oxide growth kinetics}

Fig. 9 plots the oxide scale thickness on the AlCoCrFeNiYHf HEA as a function of the square root of the oxidation time at $1100{ }^{\circ} \mathrm{C}$. The oxide scale thickness was measured using Image J software based on the five cross-sectional SEM images of oxide scale. The average value is obtained by 100 equidistant points and the error bar is standard deviation of 100 equidistant points. The linear relationship suggests that the growth of the oxide scale follows a parabolic law. Therefore, the parabolic rate constant for oxidation, $k_{h}$, is expressed in terms of the oxide scale thickness (h) and the oxidation time (t) [36]:

$$
\Delta h^{2}=2 k_{h} t
$$

Based on the linear fit to the data in Fig. 9, the parabolic rate constant $k_{h}$ is calculated to be $3 \times 10^{-14} \mathrm{~cm}^{2} \mathrm{~s}^{-1}$, which is one order of magnitude lower than $k_{h}\left(9 \times 10^{-13} \mathrm{~cm}^{2} \mathrm{~s}^{-1}\right)$ of the CoNiCrAlY alloy at $1100{ }^{\circ} \mathrm{C}$ reported by Evans and Taylor [37].

To facilitate comparison of the oxidation kinetics between the AlCoCrFeNiYHf HEA used in this study and the typical alumina-forming alloys used in the literature, Equation (1) is expressed in terms of the area specific mass change $(\Delta m)$ and the corresponding parabolic rate constant $\left(k_{p}\right)$ is given by:

$$
\Delta m^{2}=k_{p} t(2)
$$

Where $\Delta m$ is a function of the oxide scale thickness, given by:

$$
\Delta m=\frac{3 M_{O} \rho_{\mathrm{Al}_{2} \mathrm{O}_{3}}}{M_{\mathrm{Al}_{2} \mathrm{O}_{3}}} \Delta h(3)
$$

where $\boldsymbol{M}_{\boldsymbol{O}}(16 \mathrm{~g} / \mathrm{mol})$ and $\boldsymbol{M}_{\mathrm{Al}_{2} \mathrm{O}_{3}}(108 \mathrm{~g} / \mathrm{mol})$ are molar mass of $\mathrm{O}$ element and $\mathrm{Al}_{2} \mathrm{O}_{3}$, respectively. $\quad \rho_{\mathrm{Al}_{2} O_{3}}\left(3.98 \mathrm{~g} / \mathrm{cm}^{3}\right)$ is the density of $\alpha-\mathrm{Al}_{2} \mathrm{O}_{3}$.

Combined Equations (1-3), we have [36, 37]:

$$
k_{p}=2\left(\frac{3 M_{O} \rho_{\mathrm{Al}_{2} \mathrm{O}_{3}}}{M_{\mathrm{Al}_{2} \mathrm{O}_{3}}}\right)^{2} k_{h}
$$

The estimated parabolic rate constant, $k_{p}$, is estimated to be $1.9 \times 10^{-13} \mathrm{~g}^{2} \mathrm{~cm}^{-4} \mathrm{~s}^{-1}$ based 
on Equation (4).

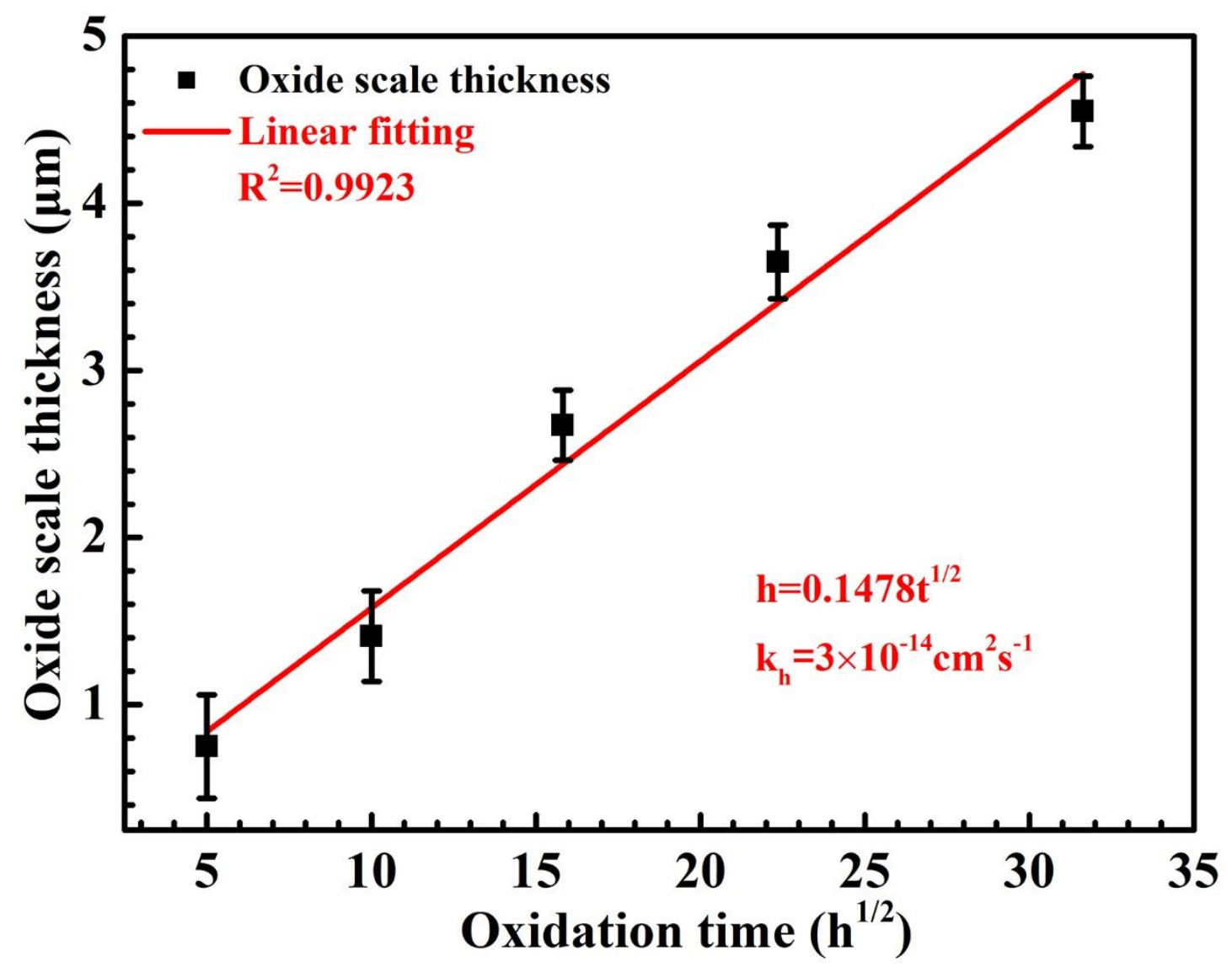

Fig. 9. Oxidation kinetics of the AlCoCrFeNiYHf HEA during $1000 \mathrm{~h}$ oxidation at $1100{ }^{\circ} \mathrm{C}$.

Parabolic rate constants $\left(k_{p} / \mathrm{g}^{2} \mathrm{~cm}^{-4} \mathrm{~s}^{-1}\right)$ of typical alumina-forming alloys at $1100{ }^{\circ} \mathrm{C}$ are summarized and compared in Table 2. Generally, the $k_{p}$ value of the AlCoCrFeNiYHf HEA used in this work is about one order of magnitude lower than those of conventional NiCoCrAlY, un-doped NiAl and un-doped FeCrAl alloys, suggesting a significant improvement in oxidation resistance over those alloys. On the other hand, the $k_{p}$ value of the AlCoCrFeNiYHf HEA is comparable to those of NiAlHf and RE-doped FeCrAl $\left(\mathrm{RE}=\mathrm{Y}, \mathrm{Hf}\right.$ or $\mathrm{Y}_{2} \mathrm{O}_{3}$ ) which have been reported to show superior oxidation resistance by Pint et al. $[5,20]$. However, it should be mentioned that it is difficult to make an accurate comparison for the oxidation kinetics among these alloys due to the compositional difference (e.g. RE concentration and species).

Table 2. Parabolic rate constants $k_{p}\left(\mathrm{~g}^{2} \mathrm{~cm}^{-4} \mathrm{~s}^{-1}\right)$, of typical alumina-forming alloys at $1100{ }^{\circ} \mathrm{C}$. 


\begin{tabular}{cccc}
\hline Sources & Materials & Techniques & $k_{p}\left(\mathrm{~g}^{2} \mathrm{~cm}^{-4} \mathrm{~s}^{-1}\right)$ \\
\hline Present work & AlCoCrFeNiYHf & Arc melting & $1.9 \times 10^{-13}$ \\
Guo et al.[38] & NiCoCrAlY coating & EB-PVD & $2.9 \times 10^{-12}$ \\
Zhao et al.[24] & NiCoCrAlY & SPS & $3.8 \times 10^{-12}$ \\
Zhao et al.[24] & NiCoCrAlY & Powder Milling & $1.4 \times 10^{-12}$ \\
Hejrani et al.[31] & CoNiCrAlY & HV-APS & $6.1 \times 10^{-12}$ \\
Das et al.[39] & $\begin{array}{c}\text { Pt-diffused } \\
\text { nickel aluminide }\end{array}$ & Pack cementation & $2.6 \times 10^{-12}$ \\
Pint et al.[20] & NiAl & Arc melting & $3.6 \times 10^{-12}$ \\
Pint et al.[20] & NiAlHf & Arc melting & $1.6 \times 10^{-13}$ \\
Pint[5] & FeCrAl & Arc melting & $3.2 \times 10^{-12}$ \\
Pint[5] & RE(Y, Hf or Y $\left.{ }_{2} \mathrm{O}_{3}\right)$ & Arc melting & $0.98-4.4 \times 10^{-13}$ \\
\hline
\end{tabular}

\subsection{Phase evolution of AlCoCrFeNiYHf HEA as a function of oxidation time}

Fig. 10. XRD results of AlCoCrFeNiYHf HEA substrate after oxidation at $1100{ }^{\circ} \mathrm{C}$ for $0 \mathrm{~h}, 250 \mathrm{~h}, 500 \mathrm{~h}$ and $1000 \mathrm{~h}$. (The annealed samples are removed from furnace at high temperature and immediately water-quenched. Then, the oxide scale and Al-depletion layer on the HEA substrate was mechanically ground off, with final polishing of 0.05 $\mu \mathrm{m}$ using standard metallographic approaches before XRD measurement.) 


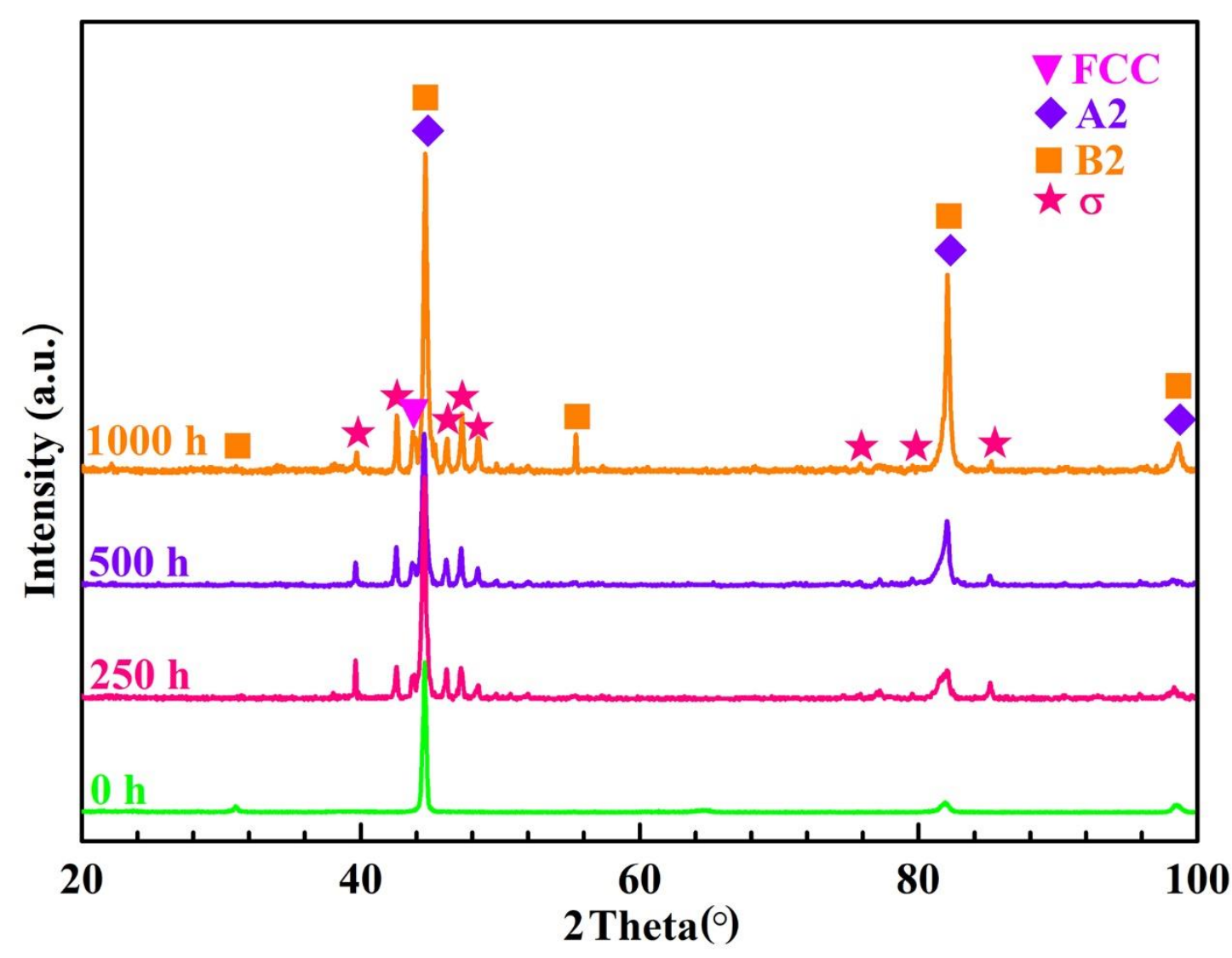

Fig. 10. XRD results of AlCoCrFeNiYHf HEA substrate after oxidation at $1100{ }^{\circ} \mathrm{C}$ for $0 \mathrm{~h}, 250 \mathrm{~h}, 500 \mathrm{~h}$ and $1000 \mathrm{~h}$. (The annealed samples are removed from furnace at high temperature and immediately water-quenched. Then, the oxide scale and Al-depletion layer on the HEA substrate was mechanically ground off, with final polishing of 0.05 $\mu \mathrm{m}$ using standard metallographic approaches before XRD measurement.)

Fig. 10 shows phase evolution of the AlCoCrFeNiYHf HEA samples after oxidation at $1100{ }^{\circ} \mathrm{C}$ as a function of oxidation time. For as-cast AlCoCrFeNiYHf HEA $(0 \mathrm{~h})$, it consists of A2 and B2 phases. After oxidation for $250 \mathrm{~h}$, minor quantity of FCC and $\sigma$ phases also develop in the HEA substrate except for the primary A2 and B2 phases related to the XRD results. Additionally, the phase compositions of HEA substrate are not altered with an increased oxidation time from $250 \mathrm{~h}$ to $1000 \mathrm{~h}$. 
Table 3. SEM-EDS analysis results for chemical compositions (at. \%) of A2, B2, FCC and $\sigma$ phases in the HEA after oxidation at $1100{ }^{\circ} \mathrm{C}$ for $1000 \mathrm{~h}$.

\begin{tabular}{cccccc}
\hline \multirow{2}{*}{ Phases } & \multicolumn{5}{l}{ Elements (at. \%) } \\
\cline { 2 - 6 } & $\mathrm{A} 1$ & $\mathrm{Co}$ & $\mathrm{Cr}$ & $\mathrm{Fe}$ & $\mathrm{Ni}$ \\
\hline A2 & $7.8 \pm 1.9$ & $18.3 \pm 2.0$ & $38.6 \pm 2.2$ & $26.4 \pm 1.8$ & $8.9 \pm 2.1$ \\
B2 & $27.5 \pm 2.2$ & $19.7 \pm 1.9$ & $12.1 \pm 2.1$ & $15.0 \pm 1.8$ & $25.7 \pm 1.9$ \\
FCC & $8.1 \pm 1.8$ & $23.6 \pm 2.0$ & $26.3 \pm 2.1$ & $27.6 \pm 1.9$ & $14.4 \pm 1.8$ \\
$\sigma$ & $6.9 \pm 1.9$ & $24.3 \pm 2.2$ & $30.6 \pm 1.9$ & $28.0 \pm 1.9$ & $10.2 \pm 2.0$ \\
\hline
\end{tabular}

The distribution of phases in the HEA substrate after oxidation at $1100{ }^{\circ} \mathrm{C}$ for $1000 \mathrm{~h}$ is presented in Fig. 11. It is evident in Fig. 11 that four types of phases can be observed in the HEA, which agrees well with the XRD results (Fig. 10). As shown in Fig. 11a and $\mathrm{b}$, the FCC phase predominantly segregates at the grain boundaries. The brightest region presented in the Fig. 11d is identified to be $\sigma-\mathrm{CoCr}$ or $\sigma-\mathrm{FeCr}$ phase, which is consistent with results reported by Liaw [40]. A2 and $\sigma$ phases precipitate from the large B2 grains, which can be seen in Fig. 11c and d. The SEM-EDS analysis results (Table 3) reveal similar composition with the STEM-EDS results (Table 1). A2 phase is rich in Fe and $\mathrm{Cr}$ and $\mathrm{B} 2$ phase is rich in $\mathrm{Ni}$ and $\mathrm{Al}$, while the $\mathrm{FCC}$ and $\sigma$ phases are enriched with $\mathrm{Fe}, \mathrm{Co}$ and $\mathrm{Cr}$. The existing temperature of $\sigma$ phase in the AlCoCrFeNiYHf HEA ranges form $500-810{ }^{\circ} \mathrm{C}$ based on the thermodynamic-modeling predictions $[40,41]$. However, the $\sigma$ phase is still present after heat treatment at $1100{ }^{\circ} \mathrm{C}$, which exceeds the thermodynamically temperature range. K.Liaw and Tang et.al also report the occurrence of $\sigma$ phase in the AlCoCrFeNi HEA after heat treatment at $1150{ }^{\circ} \mathrm{C}$ for $50 \mathrm{~h}$ [40]. The $\sigma$ phase forms at the Cr-rich corner since the $\sigma$ phase is stable in both the $\mathrm{Cr}$ $\mathrm{Fe}$ and $\mathrm{Co}-\mathrm{Cr}$ binary systems. Especially for the Co-Cr system, a certain amount of Co can stabilize the $\sigma$ phase up to $1283{ }^{\circ} \mathrm{C}$ [42]. As presented in Table 3, a relatively high amount of $\operatorname{Co}(\sim 24.3$ at. \%) can be found in the region of $\sigma$ phase. 

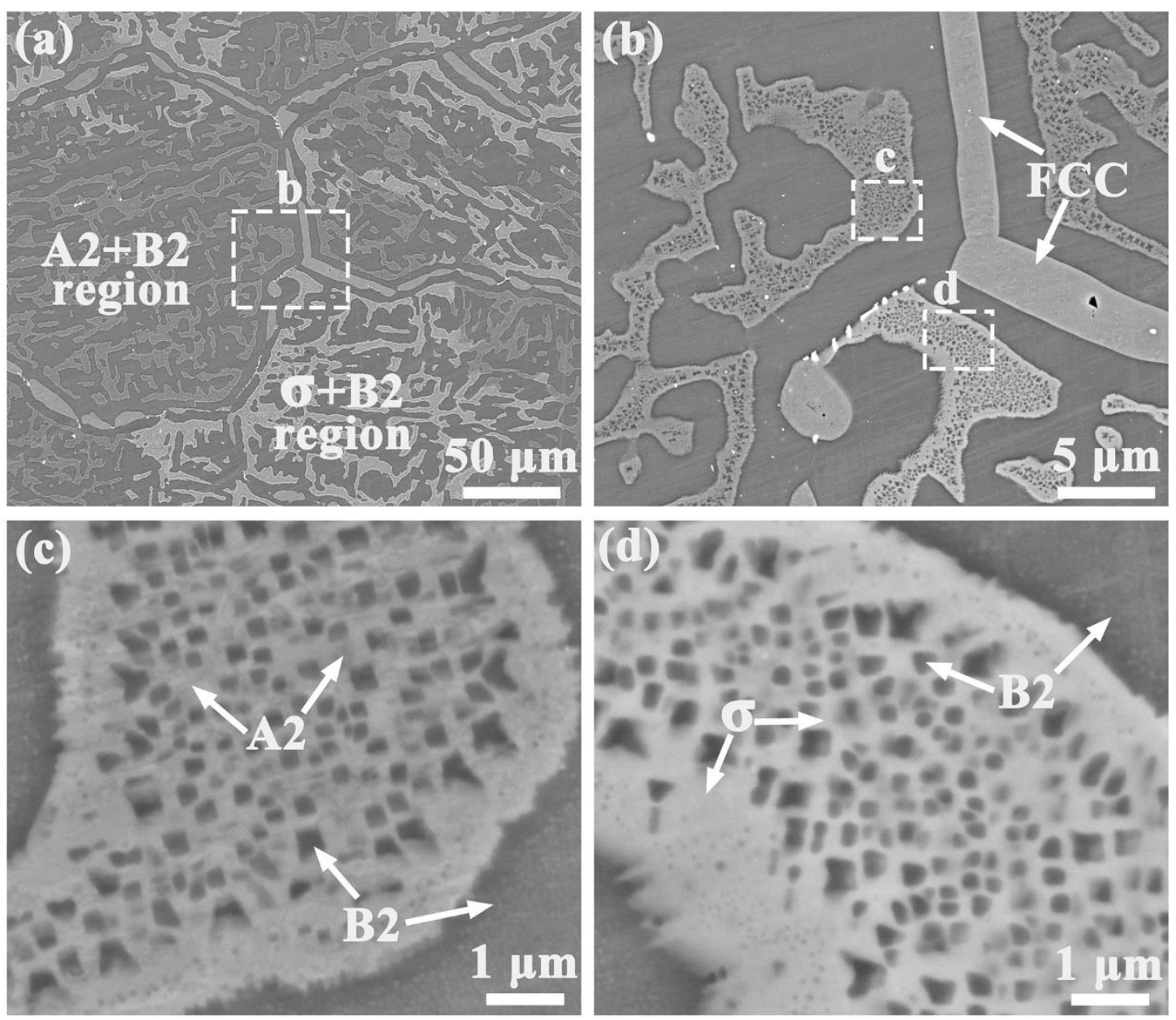

Fig. 11. Surface morphology of AlCoCrFeNiYHf HEA substrate after oxidation at $1100{ }^{\circ} \mathrm{C}$ for 1000 h: (a) low magnification backscattered SEM images, giving an overview of HEA substrate; (b) high magnification backscattered SEM images over the area within the white rectangle in (a); (c and d) high magnification backscattered SEM images over the area within the white rectangle in (b), showing the detail microstructure of HEA substrate.

\section{Discussion}

In this study, it has been clearly demonstrated that the AlCoCrFeNiYHf HEA exhibits an extremely low oxide growth rate and strong oxide/substrate interface adhesion, which eventually contribute to the superior spallation resistance of oxide scale for the long-term oxidation. The mechanisms will be discussed as follows. 


\subsection{Exclusive $\alpha-\mathrm{Al}_{2} \mathrm{O}_{3}$ formation in the early oxidation stage}

\section{(1) Fast establishment of $\alpha-\mathrm{Al}_{2} \mathrm{O}_{3}$ in the early oxidation stage}

In the early oxidation stage, the formation of transitive $\theta-\mathrm{Al}_{2} \mathrm{O}_{3}$ in the $\mathrm{Al}_{2} \mathrm{O}_{3}$ scale is usually observed for the NiCoCrAlY and NiAlHf alloys $[19,24]$. The contribution of $\theta-\mathrm{Al}_{2} \mathrm{O}_{3}$ content in $\mathrm{Al}_{2} \mathrm{O}_{3}$ scale to overall oxide scale thickness cannot be neglected, due to about an order of magnitude higher growth rate of $\theta-\mathrm{Al}_{2} \mathrm{O}_{3}$ than $\alpha-\mathrm{Al}_{2} \mathrm{O}_{3}[19,43]$. Especially, it is well understood that the doping of REs Y or Hf into NiAl alloy can inhibit the transformation of $\theta$ to $\alpha-\mathrm{Al}_{2} \mathrm{O}_{3}$, which will further thicken the oxide scale. Zhao et al. report that the content of $\theta-\mathrm{Al}_{2} \mathrm{O}_{3}$ in the $\mathrm{Al}_{2} \mathrm{O}_{3}$ for the Hf-doped $\mathrm{NiAl}$ alloy exceeds $80 \%$ after oxidation at $1150{ }^{\circ} \mathrm{C}$ for $10 \mathrm{~min}$ [19]. However, for the AlCoCrFeNiYHf HEA used in this study, the oxide scale only consists of $\alpha-\mathrm{Al}_{2} \mathrm{O}_{3}$ and no $\theta-\mathrm{Al}_{2} \mathrm{O}_{3}$ can be detected after $5 \mathrm{~min}$ oxidation at $1100{ }^{\circ} \mathrm{C}$. Two reasons are considered to contribute to the fast phase transformation rate of $\theta$ to $\alpha-\mathrm{Al}_{2} \mathrm{O}_{3}$ for the AlCoCrFeNiYHf HEA as follows: (1) The solid solution of Fe and $\mathrm{Cr}$ in the HEA can facilitate the transformation of $\theta$ to $\alpha-\mathrm{Al}_{2} \mathrm{O}_{3}[19,44,45]$; (2) The high-density phase interfaces in the nanostructured AlCoCrFeNiYHf HEA increases the number of sites available for heterogeneous nucleation of $\alpha-\mathrm{Al}_{2} \mathrm{O}_{3}$ and, therefore, facilitate earlier establishment of an $\alpha-\mathrm{Al}_{2} \mathrm{O}_{3}$ scale $[36,46]$.

\section{(2) Maintenance for exclusive $\alpha-\mathrm{Al}_{2} \mathrm{O}_{3}$ formation}

Once the nucleation of $\alpha-\mathrm{Al}_{2} \mathrm{O}_{3}$ is established, the maintenance for exclusive $\alpha-\mathrm{Al}_{2} \mathrm{O}_{3}$ formation will be crucial to inhibit the formation of transitive oxides (e.g. spinel). Based on the microstructure analysis in Section 3.1, the AlCoCrFeNiYHf HEA consists of $\mathrm{A} 2$ and $\mathrm{B} 2$ phases. The $\mathrm{B} 2$ phase is rich in $\mathrm{A} 1$ and favors the formation of $\alpha-\mathrm{Al}_{2} \mathrm{O}_{3}$. Therefore, the exclusive growth of $\alpha-\mathrm{Al}_{2} \mathrm{O}_{3}$ scale will be controlled by the selective oxidation of the $\mathrm{A} 2$ phase. The formation of $\alpha-\mathrm{Al}_{2} \mathrm{O}_{3}$ on the $\mathrm{A} 2$ phase can be maintained when the $\mathrm{Al}$ concentration in the $\mathrm{A} 2$ phase $N_{A l}^{A_{2}}$ exceeds a critical value, which can be expressed as $[36,46]$ :

$$
N_{A l}^{A_{2}} \geq N_{A l(\min )}^{A_{2}} \xi(z)
$$




$$
\text { with } N_{A l(\min )}^{A_{2}}=\frac{V_{a l l}}{V_{o x}} \sqrt{\frac{2 \pi k_{h}}{D}}
$$

where $V_{\text {all }}$ and $V_{o x}$ are the molar volume of the AlCoCrFeNiYHf HEA and $\alpha-\mathrm{Al}_{2} \mathrm{O}_{3}$, respectively. $k_{h}$ is the parabolic rate constant, expressed in terms of the oxide scale thickness. $D$ is the inter-diffusion coefficient. $N_{A l(m i n)}^{A_{2}}$ is the critical Al concentration in a single $\mathrm{A} 2$ phase to form the exclusive $\alpha-\mathrm{Al}_{2} \mathrm{O}_{3}$ scale [47]. Substituting with required values $\left(V_{\text {all }}=7.2 \mathrm{~cm}^{3} / \mathrm{mol}, V_{o x}=25.6 \mathrm{~cm}^{3} / \mathrm{mol}, D=10^{-11} \mathrm{~cm}^{2} \mathrm{~s}^{-1}\right.$, and $k_{h}$ $\left.=3.0 \times 10^{-14} \mathrm{~cm}^{2} \mathrm{~s}^{-1}\right)[34,40,46]$, the calculated critical Al concentration $N_{A l(\min )}^{A_{2}}$ is about 3.97 at. $\%$, which is significantly lower than that $(\sim 15$ at. $\%)$ of conventional CoNiCrAlY [37].

The $\xi(z)$ in Eq. (1) can be solved in terms of a parameter $z$ as

$$
\begin{aligned}
& \xi(z)=\left[1+\sum_{n=1}^{\infty} z \exp \left(-\frac{z^{2}}{(4 n)^{2}}\right) \int_{z / 4 n^{2}}^{\infty} \exp \left(-n^{2} y^{2}\right) d y\right]^{-1} \\
& \text { with } \\
& \quad z=P_{L} \sqrt{D t} \text { (4) }
\end{aligned}
$$

where $\mathrm{y}$ is merely an auxiliary variable which will disappear after carrying out the integration. Microstructure parameter $P_{L}$ is the number of intercepts by the A2 phase in the AlCoCrFeNiYHf HEA per unit length of a linear probe, which can be estimated in terms of a cubic phase with an edge length $d$, as [46]:

$$
P_{L}=\frac{3 f}{d}(5)
$$

where $f$ is the volume fraction of the A2 phase in the HEA, which is measured using image $\mathrm{J}$ based on HAADF images and has a volume fraction of $\sim 44 \%$ in spite of ID or DR regions. The edge widths of A2 phase $d$ in the ID and DR regions are $103 \mathrm{~nm}$ and $81 \mathrm{~nm}$, respectively, referring to the width of A2 phase in the two types of regions (Fig. 2). 
From the definition of $N_{A l}^{A_{2}}$, the Eq. (1) can be written as [46]:

$$
\frac{N_{A l}^{A_{2}}}{N_{A l(\min )}^{A_{2}}} \geq \xi(z)=\xi\left(P_{L} \sqrt{D t}\right)(6)
$$

or by solving the inverse function of $\xi(z)$, the Eq. (3) becomes[46]

$$
P_{L} \sqrt{D t} \geq \Phi\left(\frac{N_{A l}^{A_{2}}}{N_{A l(\min )}^{A_{2}}}\right)(7)
$$

where $\Phi$ is the inverse function of $\xi(z)$ and is plotted by Wang et.al [46]. The minimum $\mathrm{A} 1$ concentrations in the $\mathrm{A} 2$ phase required to form an exclusive $\alpha$ $\mathrm{Al}_{2} \mathrm{O}_{3}$ scale as a function of oxidation time are calculated based on the equations 1-7 and plotted figure related to $\Phi$ function from the reference [46], which is presented in Fig. 12.

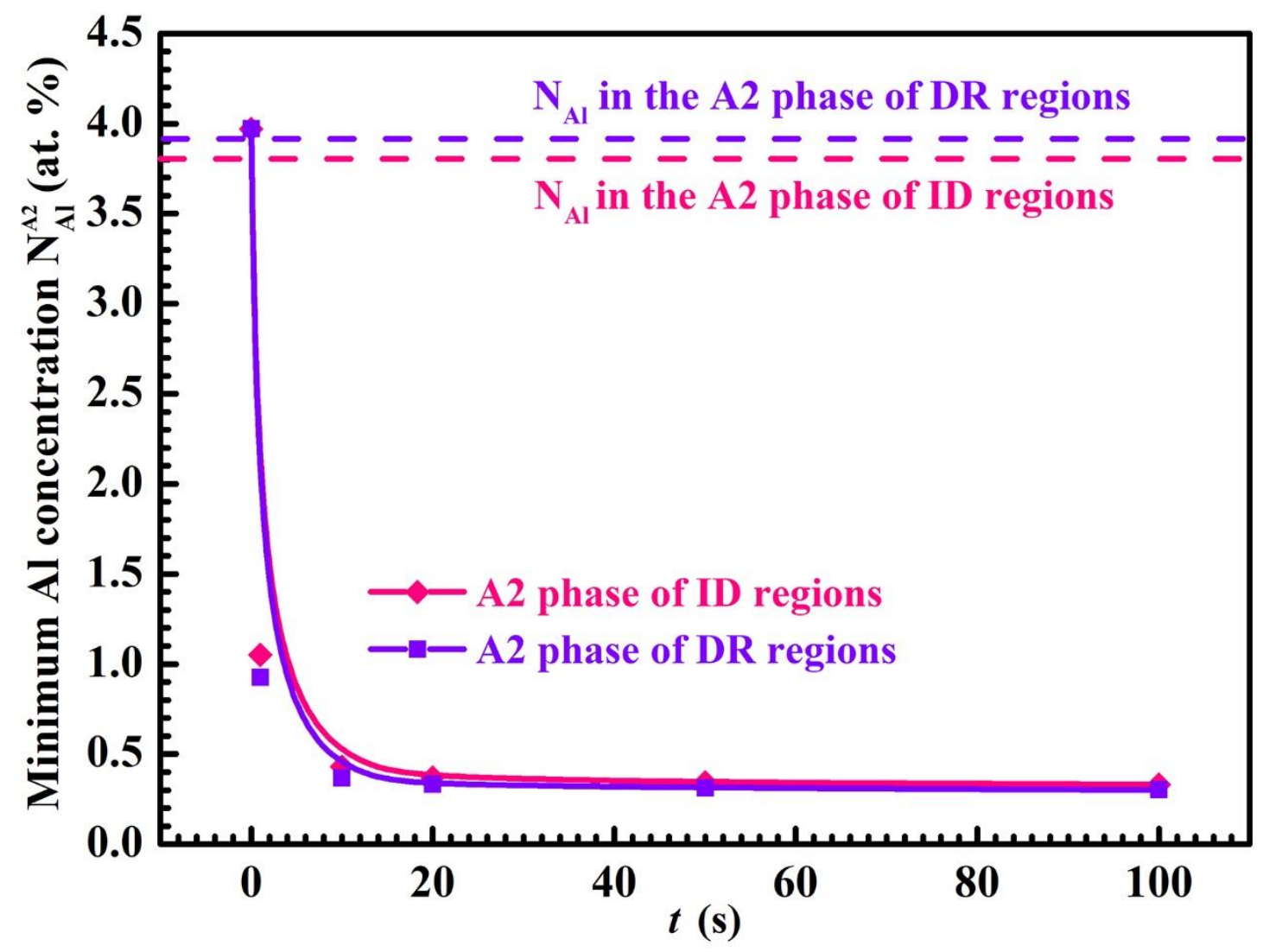

Fig. 12. Minimum Al concentration in the A2 phase of ID and DR regions to form an exclusive $\alpha-\mathrm{Al}_{2} \mathrm{O}_{3}$ scale as a function of oxidation time. The dash lines represent the $\mathrm{Al}$ concentration in the A2 phase of ID and DR regions. 
It is well understood that the transient oxidation stage is inevitable when $N_{A l}^{A_{2}}$ is lower than the minimum Al concentration in the A2 phase. However, the initial A1 concentrations in the A2 phase both for ID and DR regions are about 3.8 and 4.0 at. \%, respectively, which is very close to the critical $\mathrm{Al}$ concentration with a value of 3.97 at. \%. Additionally, the minimum Al concentration in the A2 phase required to nucleate exclusive $\alpha-\mathrm{Al}_{2} \mathrm{O}_{3}$ rapidly decreases and almost stabilizes at a low level in $20 \mathrm{~s}$, as shown in Fig. 12. In other words, the condition for the exclusive formation of $\alpha$ $\mathrm{Al}_{2} \mathrm{O}_{3}$ scale becomes less restrictive as oxidation time proceeds. Based on the discussion above, it is clearly demonstrated that the nano-sized A2 phase can significantly lower the minimum $\mathrm{A} 1$ concentrations in the $\mathrm{A} 2$ phase required to form an exclusive $\alpha-\mathrm{Al}_{2} \mathrm{O}_{3}$ scale. Moreover, even if the criterion for maintaining an exclusive $\alpha-\mathrm{Al}_{2} \mathrm{O}_{3}$ scale cannot be satisfied initially, it will be rapidly satisfied due to the nanosized A2 phase. As a result, both fast establishment of $\alpha-\mathrm{Al}_{2} \mathrm{O}_{3}$ and maintenance of $\alpha$ $\mathrm{Al}_{2} \mathrm{O}_{3}$ lead to the exclusive formation of $\alpha-\mathrm{Al}_{2} \mathrm{O}_{3}$ scale.

\subsection{Mechanisms for the ultra-low oxide growth rate during long-term oxidation}

The double-layer structure of oxide scale consisting of an inner columnar and outer equiaxed grains can be clearly observed in Fig. 7, which results from the concurrent inward oxygen diffusion and outward aluminum diffusion $[18,48]$. It is well known that the equiaxed zone is formed by outward aluminum diffusion, and meanwhile the columnar zone is formed by inward oxygen diffusion [5, 18]. It has been also demonstrated by Boll and Pint et al. [49] that outward flux of Al is much smaller than the flux for the inward diffusion of $\mathrm{O}$ in the oxide scale for the $\mathrm{Hf}$ or $\mathrm{Zr}$-doped NiAl and thus the contribution of the outward Al flux has negligible effect on the increase of oxide thickness on doped NiAl. Therefore, the ratio of the thickness of the characteristic equiaxed zone to the total oxide thickness can show respective contribution of outward diffusion of aluminum and inward diffusion of oxygen during oxidation [18].

Fig. 13 shows the evolution of double-layer structure of $\alpha-\mathrm{Al}_{2} \mathrm{O}_{3}$ scale with the increased oxidation time from $250 \mathrm{~h}$ to $1000 \mathrm{~h}$. The thickness of equiaxed layer is only 
$\sim 237 \mathrm{~nm}$ after $250 \mathrm{~h}$ oxidation and keeps constant even after $1000 \mathrm{~h}$ oxidation $(\sim 241$ $\mathrm{nm})$. In other words, the increase of total oxide thickness merely comes from the growth of columnar grains beneath for the long-term oxidation. These results indicate that the growth of oxide scale for the Y/Hf-doped HEA is dominated by the inward O diffusion. As shown in Fig. 4, the $\mathrm{Y} / \mathrm{Hf}$-rich oxides (e.g. $\mathrm{Y}_{3} \mathrm{Al}_{5} \mathrm{O}_{12}$ and $\mathrm{HfO}_{2}$ ) uniformly segregate at scale grain boundaries for the long-term oxidation. This uniform distribution of Y/Hfrich oxides at scale grain boundaries might be induced by the uniform distribution of $\mathrm{Y} / \mathrm{Hf}$ in the HEA. However, no Y/Hf-rich oxides can be observed on the oxide scale surface in the early oxidation stage (Fig. 3). This result indicates that the segregation of Y/Hf-rich oxides at scale grain boundaries is a consequence of Y and Hf diffusion along scale grain boundaries in the later oxidation stage. As the scale thickens, REs ions dynamically segregate to oxide/substrate interface and scale grain boundaries due to the oxygen potential gradient in the scale [21]. The segregation of REs ions to the oxide/substrate interface can suppress growth of interfacial void, thus improving scale adhesion. By diffusing outward along the scale grain boundaries, REs ions hinder outward aluminum diffusion and thereby slow down the oxidation rate.

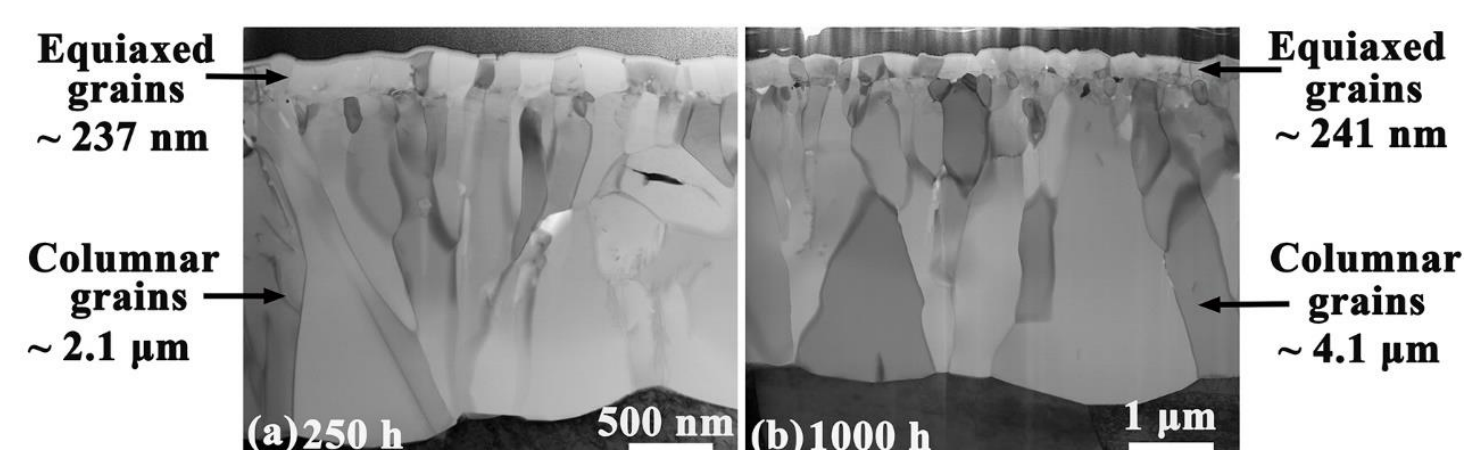

Fig. 13. Evolution of double-layer structure of $\alpha-\mathrm{Al}_{2} \mathrm{O}_{3}$ scale formed on the AlCoCrFeNiYHf HEA with the increased oxidation time: (a, b) bright-field (BF) TEM images, showing the $\alpha-\mathrm{Al}_{2} \mathrm{O}_{3}$ scale structure after oxidation for $250 \mathrm{~h}$ and $1000 \mathrm{~h}$, respectively. (The measurements in this figure represent the thicknesses of equiaxed and columnar layers, respectively.)

Unocic and Pint et al. [50] have investigated the microstructure and composition of oxide scale formed on a commercial NiCoCrAlYHfSi coating (PWA 286) [2]. For the 
polished PWA 286, the oxide scale has double-layer structure after oxidation at $1100{ }^{\circ} \mathrm{C}$. The inner layer is columnar $\alpha-\mathrm{Al}_{2} \mathrm{O}_{3}$ grains, which is similar to the observations in Fig. 7. The predominant columnar grain microstructure in the oxide scale for the Y/Hfdoped HEA and the typical Y/Hf-doped PWA286 shows a dominant mechanism of inward $\mathrm{O}$ diffusion. On the other hand, REs $(\mathrm{Y}+\mathrm{Hf})$ in the form of $\mathrm{Y} / \mathrm{Hf}$-rich oxides segregates to $\alpha-\mathrm{Al}_{2} \mathrm{O}_{3}$ grain boundaries for these two types of alloys (Fig. 4). These results indicate that the role of REs in the two types of alloys might be similar. However, the outer layer contains a large amount of Cr-rich precipitates and pores, which are likely formed in the early oxidation stage. Especially in the case when YSZ TBCs are applied, these pores in the outer layer will occur at top coat (YSZ)/oxide scale interface, which possibly affect the interfacial adhesion. For the HEA used in this study, the outer layer of oxide scale is still equiaxed $\alpha-\mathrm{Al}_{2} \mathrm{O}_{3}$ grains without the occurrence of $\mathrm{Cr}$-rich precipitates and pores (Fig. 7).

A significant difference in the oxide scale growth for the two types of alloys should be noticed. For the PWA286, a large amount of Y/Hf-rich oxide protrusions occur at scale/substrate interface, which lead to a very un-uniform oxide scale growth due to the over-doping of REs in the oxide scale. In addition, these oxide protrusions allow the oxide scale to grow rapidly, since Y/Hf-rich oxides are fast $\mathrm{O}$ conductors. Based on the previous works [51, 52], the tensile stresses at those protrusions could lead to cracks or interfacial separation, when the oxide protrusions reach a critical size. For the Y/Hfdoped HEA, no oxide protrusions occur at interface even after $1000 \mathrm{~h}$ oxidation. First, the concentration of REs in the HEA (0.02 at. \%) is lower, compared with that in the PWA286, which can alleviate the formation of protrusions. Second, the nano-sized A2 and B2 phases in the HEA provide more phase boundaries for the segregation of REs, which can facilitate the uniform distribution of REs in the alloy. It has been demonstrated by Sloof et al. that a higher amount of phase boundaries can mitigate the formation of protrusions due to the more uniform distribution of RE [53].

Based on the results reported by Naumenko and Quadakkers et al. $[54,55]$, the oxide scale is predominant columnar grain microstructure for the MCrAlY alloy with a low Y-content (typically 0.2 wt. \%). At higher Y-contents and with additions of other REs 
such as $\mathrm{Zr}$ and $\mathrm{Hf}$, the scale-microstructure may substantially deviate from the typical columnar morphology. For the FeCrAlY alloy, the columnar grain microstructure has been transformed into small, equiaxed grain microstructure, when the additional $\mathrm{Zr}$ is added in the alloy [55]. The small, equiaxed grains lead to a higher density of grain boundaries, which provides a higher amount of diffusion paths and thus increases the growth kinetics.

In present study, the content of REs $(\mathrm{Y}+\mathrm{Hf})$ in the HEA is lower than that (typically 0.2 wt. \%) of the MCrAlY alloy used by Naumenko and Quadakkers et al. Therefore, the oxide scale formed on the Y/Hf-doped HEA shows same columnar microstructure with the MCrAlY alloy with a low Y-content (typically $0.2 \mathrm{wt}$ \%). In addition, the uniform segregation of Y/Hf-rich oxides at $\alpha-\mathrm{Al}_{2} \mathrm{O}_{3}$ grain boundaries can perhaps inhibit the inward oxygen diffusion and thus lead to a lower growth rate (Fig. 4).

Apart from the beneficial REs-effects in the AlCoCrFeNiYHf HEA, the columnar grain size (width) is crucial to the growth rate of oxide scale. Lager columnar grain size leads to a lower density of grain boundaries for the oxide scale with a predominant columnar grain microstructure. Therefore, the typical NiCoCrAlYHf alloy with a same concentration of $\mathrm{Y}$ and $\mathrm{Hf}(0.02$ at. \%) was also prepared to compare with the AlCoCrFeNiYHf HEA. Fig. 14 shows the surface morphology of the NiCoCrAlYHf alloy. A typical two-phase microstructure consisting of $\gamma$ (bright contrast) and $\beta$ (dark contrast) phases can be observed.

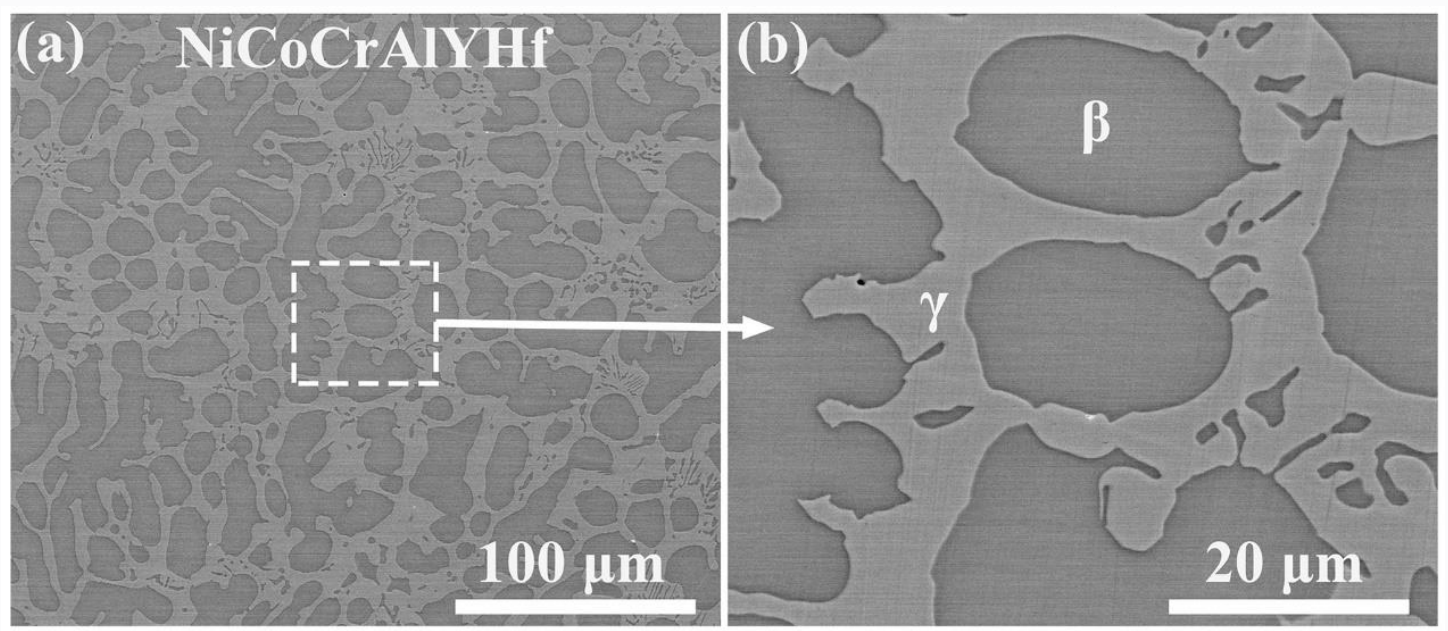

Fig. 14. Surface morphology of as-cast NiCoCrAlYHf alloy. (The as-cast 
NiCoCrAlYHf alloy with a typical chemical compositions of $\mathrm{Ni}-23 \mathrm{Co}-17 \mathrm{Cr}-12 \mathrm{Al}$ in wt. \%. In addition, 0.02 at. $\% \mathrm{Y}$ and 0.02 at. \% $\mathrm{Hf}$ are also added in the alloy for comparison. The detailed preparation process can be seen in Section 2.1)

Fig. 15 shows the fractured cross-sectional morphologies of oxide scale for the as-cast NiCoCrAlYHf alloy after $250 \mathrm{~h}$ oxidation, AlCoCrFeNiYHf HEA after 250 h oxidation and AlCoCrFeNiYHf HEA after 1000 h. The columnar grain size (width) in the oxide scale is measured using Image $\mathbf{J}$ software based on fractured cross-sectional morphologies (Fig. 15), since the TEM samples cover fairly small areas (Fig. 13).

For all samples, the oxide scales are primary columnar grain microstructure (Fig. 15). For the as-cast NiCoCrAlYHf alloy, the oxide scale thickness exceeds $4 \mu \mathrm{m}$ and the average columnar grain size (width) is $0.6 \pm 0.2 \mu \mathrm{m}$ after $250 \mathrm{~h}$ oxidation (Table 4). For the AlCoCrFeNiYHf HEA, a large amount of coarse columnar grains can be seen after $250 \mathrm{~h}$ oxidation (Table 4), which is consistent with the observations in Fig. 13a. Meanwhile, the average columnar grain size (width) is $0.9 \pm 0.2 \mu \mathrm{m}$, which increases about $53 \%$, compared with that for the NiCoCrAlYHf alloy (Table 4). When the oxidation time increases to $1000 \mathrm{~h}$, the length and width $(1.2 \pm 0.3 \mu \mathrm{m})$ of columnar grains increases simultaneously, possibly due to grain growth (Table 4).

The grain boundary of columnar grain is primary diffusion paths for the inward $\mathrm{O}$ diffusion. The much larger columnar grains in the oxide scale for the AlCoCrFeNiYHf HEA compared with that of NiCoCrAlYHf alloy can significantly reduce the diffusion paths and thus lower the oxidation rate. However, the reasons for the formation of coarse columnar grains in the oxide scale for the AlCoCrFeNiYHf is still not clear, which requires more works to understand this point. 

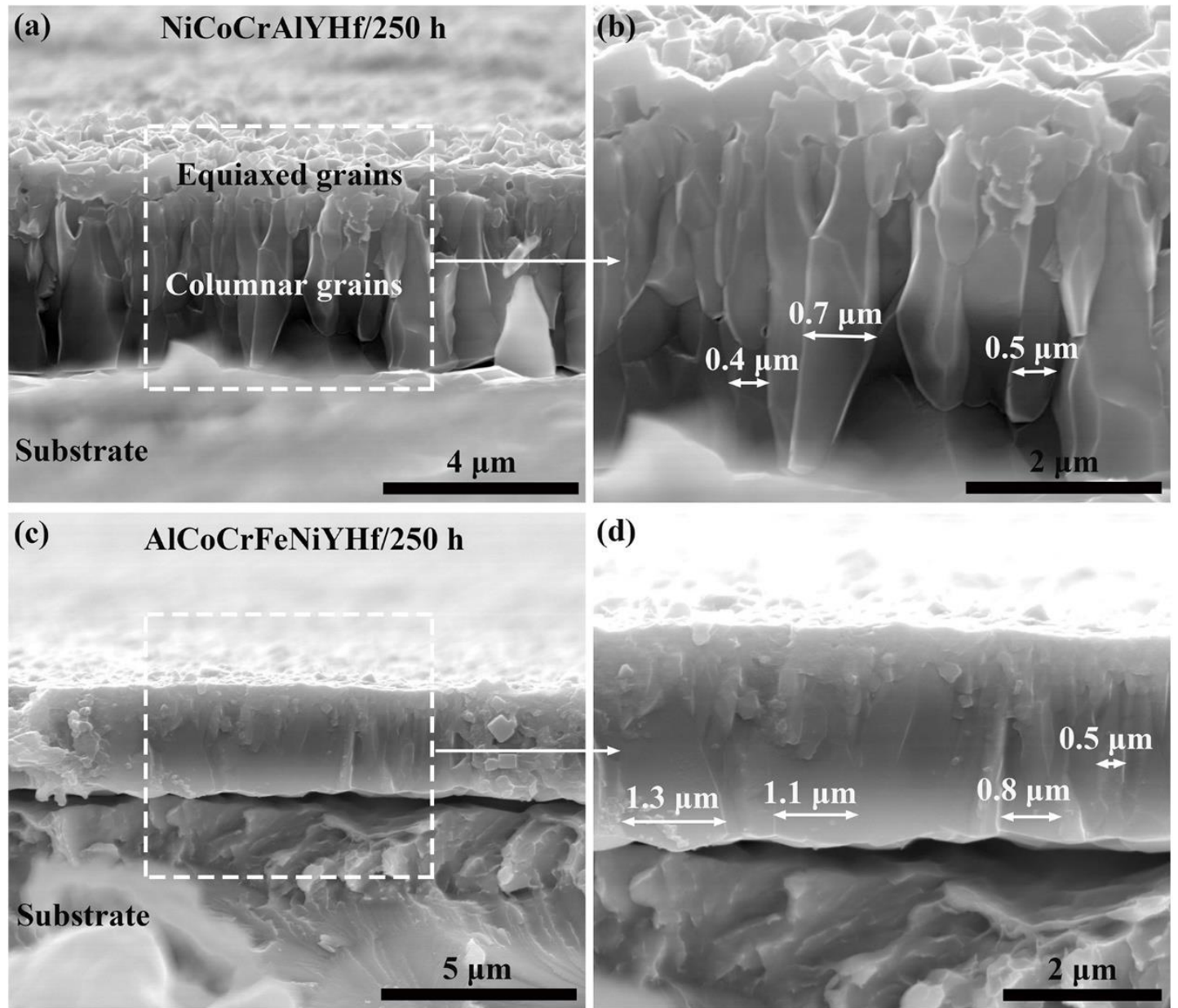

(d)

(e) AlCoCrFeNiYHf/1000 h

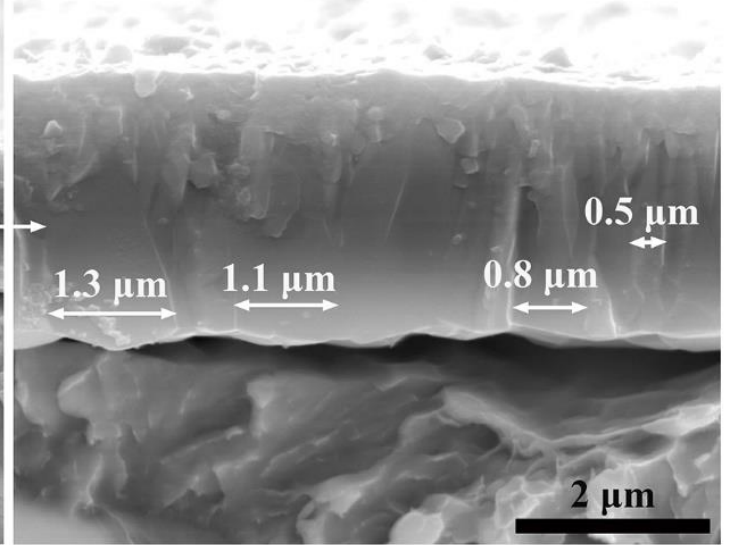

(f)
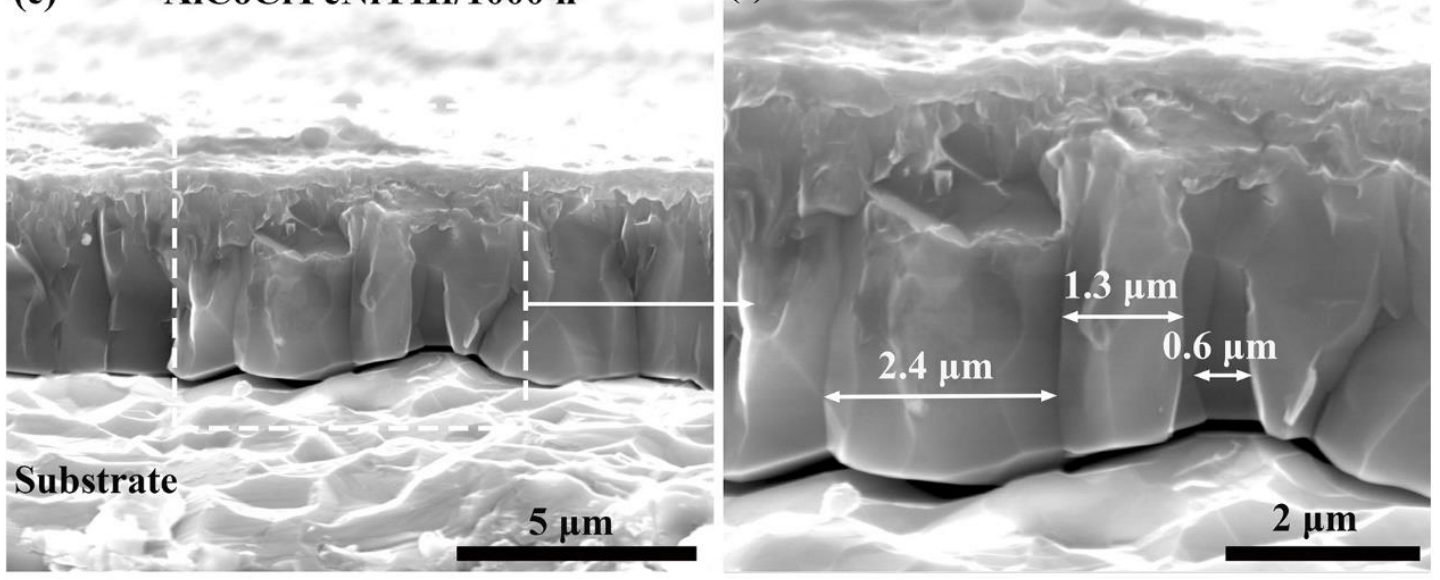

Fig. 15. Fractured cross-sectional morphologies of oxide scale for the as-cast NiCoCrAlYHf alloy after $250 \mathrm{~h}$ oxidation (a, b), AlCoCrFeNiYHf HEA after $250 \mathrm{~h}$ oxidation (c, d) and AlCoCrFeNiYHf HEA after 1000 h (e, f).

Based on the analysis mentioned above, the mechanisms governing the slow oxidation rate of HEA can be summarized as follows: (1) a fast establishment of $\alpha-\mathrm{Al}_{2} \mathrm{O}_{3}$ and a short transition oxidation stage to maintain the nucleation of exclusive $\alpha-\mathrm{Al}_{2} \mathrm{O}_{3}$, as 
discussed in Section 4.1; (2) the beneficial RE effects blocks outward aluminum diffusion and thus lowers the oxidation rate; (3) The relatively large columnar grain size reduces the diffusion paths of inward $\mathrm{O}$ diffusion and thereby further slows down the oxidation rate.

Table 4. The columnar grain size in the oxide scale for the as-cast NiCoCrAlYHf alloy after $250 \mathrm{~h}$ oxidation, AlCoCrFeNiYHf HEA after $250 \mathrm{~h}$ oxidation and AlCoCrFeNiYHf HEA after $1000 \mathrm{~h}$ oxidation. (The columnar grain size is measured by the length of oxide scale/substrate interface in a single SEM image divided by the numbers of columnar grains. Five high magnification SEM images are employed to obtain the average columnar grain size using Image $\mathbf{J}$ software and the error bar is the standard deviation).

\begin{tabular}{cccc}
\hline Samples & $\begin{array}{c}\text { NiCoCrAlYHf } \\
(250 \mathrm{~h})\end{array}$ & $\begin{array}{c}\text { AlCoCrFeNiYHf } \\
(250 \mathrm{~h})\end{array}$ & $\begin{array}{c}\text { AlCoCrFeNiYHf } \\
(1000 \mathrm{~h})\end{array}$ \\
\hline $\begin{array}{c}\text { Columnar grain } \\
\text { size }(\mu \mathrm{m})\end{array}$ & $0.6 \pm 0.2$ & $0.9 \pm 0.2$ & $1.2 \pm 0.3$ \\
\hline
\end{tabular}

\subsection{The potential applications of AlCoCrFeNiYHf HEA}

Many protective coatings for structural components designed for high temperature applications, e.g., high pressure tubine blades, nozzles, combustion chambers in gas turbines, largely rely on the formation of an adherent, continous $\alpha-\mathrm{Al}_{2} \mathrm{O}_{3}$ layer on the surface $[1,2,56]$. One specific example is the thermal barrier coatings (TBCs) used in aeroengines, which constists of a ytrria stablized zirconia (YSZ) on the top and an intermidiate bond coat (e.g. $\beta-(\mathrm{Ni}, \mathrm{Pt}) \mathrm{Al}$ or $\mathrm{NiCoCrAlY})$ on the superalloy substrate[1, 57]. Upon severice, a thermally grown oxide (TGO), mainly $\alpha-\mathrm{Al}_{2} \mathrm{O}_{3}$, formed between the YSZ top coat and the bond coat. Failure of the TBCs usually occurs at the interface between the TGO and the bond coat, especially in the case of bond coat prepared by electron beam physical vapour deposition (EBPVD)[58]. In this regards, a low growing, adherent $\alpha-\mathrm{Al}_{2} \mathrm{O}_{3}$ scale would be benifical to the lifetime of the TBCs. Compared with the state-of-the-art bond coat materials, e.g., Pt-diffused nickel aluminide, or NiCoCrAlY (Table 2), the AlCoCrFeNiYHf HEA reported in this study 
exhibits a significantly lower oxide growth rate $\left(\mathrm{k}_{\mathrm{p}}=1.9 \times 10^{-13} \mathrm{~g}^{2} \mathrm{~cm}^{-4} \mathrm{~s}^{-1}\right)$ and strong interfacial bonding (no spallation even after 1000 hours at $1100{ }^{\circ} \mathrm{C}$ ). In addition, it has been reported that the HEA alloy posseses a higher mechanical strength (e.g. yield resistance) than $\beta$-(Ni,Pt)Al or NiCoCrAlY at high temperatures, therefore which should be able to reduce the interfacial rumpling (one of the dominant failure phenoneon in TBCs with a EBPVD bond coat) upon thermal cycling [14, 57, 59]. Such merits make the AlCoCrFeNiYHf HEA a better candidate material for the bond coat of TBCs used in even higher temperature aeroengines.

In addition to the bond coat materials for TBCs, the HEA developed in this work can be also applied as overlay coatings for superalloys or other high temperature alloys. Such applications require that the coatings not only have good oxidation resistance, but also a good hot corrosion resistance (e.g. S corrosion) [2]. It is well known that $\mathrm{Cr}$ is commonly added into the NiAl alloy to improve the hot-corrosion resistance [20,60, 61]. However, $\mathrm{Cr}$ is detrimental to the oxidation performance of $\mathrm{NiAl}$ alloy [20]. In this study, the AlCoCrFeNiYHf HEA contains a Cr content up to 20 at. \%, but still can maintain a superior oxidation resistance, which is comparable to the most oxidation resistant alloys ever reported, such as NiAlHf or FeCrAlY. The higher Cr level in AlCoCrFeNiYHf HEA is undoubtedly beneficial to the hot corrosion as overlay coatings application. The investigations of the hot corrosion behavior of the AlCoCrFeNiYHf HEA samples will be reported elsewhere.

However, for coating applications, the inter-diffusion between the coating and the substrate is a critical factor, which would affect the fatigue or creep strength of the components, e.g., turbine blades [62-64]. Since the HEA developed in this work contains a high level of $\mathrm{Fe}$, the inter-diffusion between the coating and the nickel superalloy substrate is expected to be an issue. However, this can be minimized or avoided by desiging proper HEA alloy compositions [65]. In addtion to coatings application, the HEA alloy also has potential in structural components operated at high temperature due to its superior mechanical strength, good oxidation resitance and corrosion resitance at high temperature. More systemical works are being carried out to investigate the suepralloy compatible HEAs in Shanghai Jiao Tong University, aiming 
to bond coat applications in TBCs.

As for the phase transformation of this type of alloy after high-temperature oxidation, the formation of FCC phase in the alloy can be attributed to the decreased Al content due to oxidation. Similar phase transformation of B2 phase to FCC phase due to Aldepletion is commonly observed in the conventional NiCoCrAlY-type alloys $[2,50,66]$. Liaw et al. reported that the ultimate tensile strength of $\mathrm{AlCoCrFeNi} \mathrm{HEA}$ at $700{ }^{\circ} \mathrm{C}$ is virtually unaffected in spite of the occurrence of $\sigma$ phase, while a noticeable increase in ductility possibly due to the formation of FCC phase [40, 67]. However, effect of the occurrence of these two phases ( $\sigma$ and FCC phases) on the mechanical properties of Y/Hf-doped HEA is not clear. Further works are required to investigate the mechanical properties for high-temperature application of AlCoCrFeNiYHf HEA.

\section{Conclusions}

In the present work, an ultra oxidation and spallation resistant $\mathrm{AlCoCrFeNi}$ highentropy alloy with $\mathrm{Y} / \mathrm{Hf}$ doping was fabricated and characterized. The following conclusions can be drawn :

1. The AlCoCrFeNiYHf HEA consists of a B2 structure matrix and a A2 structure precipitates. $\mathrm{Ni}$ and $\mathrm{Al}$ are riched in $\mathrm{B} 2$ phase, and $\mathrm{Fe}$ and $\mathrm{Cr}$ preferentially segregate in the A2 phases, while Co is uniformly distributed.

2. An exclusive $\alpha-\mathrm{Al}_{2} \mathrm{O}_{3}$ scale is fast established on the AlCoCrFeNiYHf HEA in the early oxidation stage.

3. The AlCoCrFeNiYHf HEA exhibits an extremely low oxidation rate with a parabolic rate constant $\left(1.9 \times 10^{-13} \mathrm{~g}^{2} \mathrm{~cm}^{-4} \mathrm{~s}^{-1}\right)$, which is about an order of magnitude lower than those of conventional NiCoCrAlY alloys and is comparable to those of Hf-doped NiAl and REs-doped FeCrAl alloys.

4. The oxide scale formed on the AlCoCrFeNiYHf HEA predominantly comprises of $\alpha-\mathrm{Al}_{2} \mathrm{O}_{3}$, accompanied by minor quantity of $\mathrm{Y} / \mathrm{Hf}$-rich oxides (e.g. $\mathrm{Y}_{3} \mathrm{Al}_{5} \mathrm{O}_{12}$ and $\mathrm{HfO}_{2}$ ) at the oxide grain boundaries.

5. The oxide scale formed on the AlCoCrFeNiYHf HEA is uniform in thickness and 
is merely $4.6 \pm 0.3 \mu \mathrm{m}$ thick after $1000 \mathrm{~h}$ at $1100{ }^{\circ} \mathrm{C}$. Additionally, the oxide/substrate interface is smooth and clean, and no interfacial imperfections (e.g. pores and oxide intrusions ) forms.

6. The superior oxidation performance of AlCoCrFeNiYHf HEA can be attributed to the fast establishment of exclusive $\alpha-\mathrm{Al}_{2} \mathrm{O}_{3}$ scale in the early oxidation stage, a beneficial REs-effects and the large columnar grain size in the oxide scale for the HEA.

\section{CRediT authorship contribution statement}

Jie Lu: Conceptualization, Data curation, Writing - original draft. Ying Chen: Writing - review \& editing. Han Zhang: Methodology, Formal analysis. Na Ni: Writing review \& editing. Ling Li: Methodology, Formal analysis. Limin He: Resources. Rende Mu: Resources. Xiaofeng Zhao: Conceptualization, Writing - review \& editing. Fangwei Guo: Methodology, Formal analysis.

\section{Declaration of Competing Interest}

The authors declare that they have no known competing financial interests or personal relationships that could have appeared to influence the work reported in this paper.

\section{Acknowledgement}

This work was financially Support by National Natural Science Foundation of China ( 51971139).

\section{References}

[1] N.P. Padture, M. Gell, E.H. Jordan, Thermal barrier coatings for gas-turbine engine applications, Sci. 296 (2002) 280-284.

[2] J.T. DeMasi-Marcin, D.K. Gupta, Protective coatings in the gas turbine engine, Surf. Coat. Technol. 68-69 (1994) 1-9. 
[3] K.G. Field, S.A. Briggs, K. Sridharan, R.H. Howard, Y. Yamamoto, Mechanical properties of neutron-irradiated model and commercial FeCrAl alloys, J. Nucl. Mater. 489 (2017) 118-128.

[4] Y. Yamamoto, B.A. Pint, K.A. Terrani, K.G. Field, Y. Yang, L.L. Snead, Development and property evaluation of nuclear grade wrought FeCrAl fuel cladding for light water reactors, J. Nucl. Mater. 467 (2015) 703-716.

[5] B.A. Pint, Optimization of Reactive-Element Additions to Improve Oxidation Performance of Alumina-Forming Alloys,J. Am. Ceram. Soc. 86 (2003) 686-695.

[6] J.W. Yeh, S.K. Chen, S.J. Lin, J.Y. Gan, T.S. Chin, T.T. Shun, C.H. Tsau, S.Y. Chang, Nanostructured High-Entropy Alloys with Multiple Principal Elements: Novel Alloy Design Concepts and Outcomes, Adv. Eng. Mater. 6 (2004) 299-303.

[7] B. Cantor, I.T.H. Chang, P. Knight, A.J.B. Vincent, Microstructural development in equiatomic multicomponent alloys, Mater. Sci. Eng. A. 375-377 (2004) 213-218.

[8] D.B. Miracle, O.N. Senkov, A critical review of high entropy alloys and related concepts, Acta Mater. 122 (2017) 448-511.

[9] Y.F. Ye, Q. Wang, J. Lu, C.T. Liu, Y. Yang, High-entropy alloy: challenges and prospects, Mater. Today 19 (2016) 349-362.

[10] Y. Zhang, T.T. Zuo, Z. Tang, M.C. Gao, K.A. Dahmen, P.K. Liaw, Z.P. Lu, Microstructures and properties of high-entropy alloys, Prog. Mater. Sci.61 (2014) 1-93. [11] Z. Li, S. Zhao, R.O. Ritchie, M.A. Meyers, Mechanical properties of highentropy alloys with emphasis on face-centered cubic alloys, Prog. Mater. Sci.102 (2019) 296-345.

[12] Z. Li, Interstitial equiatomic CoCrFeMnNi high-entropy alloys: carbon content, microstructure, and compositional homogeneity effects on deformation behavior, Acta Mater. 164 (2019) 400-412.

[13] Y.J. Zhou, Y. Zhang, Y.L. Wang, G.L. Chen, Solid solution alloys of AlCoCrFeNiTix with excellent room-temperature mechanical properties, Appl. Phys. Lett.90 (2007) 181904.

[14] K.R. Lim, K.S. Lee, J.S. Lee, J.Y. Kim, H.J. Chang, Y.S. Na, Dual-phase highentropy alloys for high-temperature structural applications, J. Alloys Compd. 728 (2017) 
$1235-1238$.

[15] Y.P. Wang, B.S. Li, M.X. Ren, C. Yang, H.Z. Fu, Microstructure and compressive properties of AlCrFeCoNi high entropy alloy, Mater. Sci. Eng. A. 491 (2008) 154-158. [16] T.M. Butler, J.P. Alfano, R.L. Martens, M.L. Weaver, High-Temperature Oxidation Behavior of Al-Co-Cr-Ni-(Fe or Si) Multicomponent High-Entropy Alloys, Jom. 67 (2014) 246-259.

[17] T.M. Butler, M.L. Weaver, Oxidation behavior of arc melted AlCoCrFeNi multicomponent high-entropy alloys, J. Alloys Compd. 674 (2016) 229-244.

[18] J.A. Nychka, D.R. Clarke, Quantification of Aluminum Outward Diffusion During Oxidation of FeCrAl Alloys, Oxid. Met. 63 (2005) 325-352.

[19] C. Zhao, Y. Zhou, Z. Zou, L. Luo, X. Zhao, F. Guo, P. Xiao, Effect of alloyed Lu, $\mathrm{Hf}$ and $\mathrm{Cr}$ on the oxidation and spallation behavior of NiAl, Corros. Sci. 126 (2017) 334-343.

[20]B.A. Pint, K.L. More, I.G. Wright, Effect of Quaternary Additions on the Oxidation Behavior of Hf-Doped NiAl, Oxid. Met. 59 (2003) 257-283.

[21] B.A. Pint, Experimental observations in support of the dynamic-segregation theory to explain the reactive-element effect, Oxid. Met. 45 (1996) 1-37.

[22] D.P. Whittle, J. Stringer, Improvements in High Temperature Oxidation Resistance by Additions of Reactive Elements or Oxide Dispersions, Philosophical Transactions of the Royal Society A: Mathematical, Physical and Engineering Sciences, 295 (1980) 309-329.

[23] Y. Chen, X. Zhao, P. Xiao, Effect of microstructure on early oxidation of MCrAlY coatings, Acta Mater. 159 (2018) 150-162.

[24] J. Lu, Y. Chen, C. Zhao, H. Zhang, L. Luo, B. Xu, X. Zhao, F. Guo, P. Xiao, Significantly improving the oxidation and spallation resistance of a MCrAlY alloy by controlling the distribution of yttrium, Corros. Sci. 153 (2019) 178-190.

[25] W.-R. Wang, W.-L. Wang, S.-C. Wang, Y.-C. Tsai, C.-H. Lai, J.-W. Yeh, Effects of $\mathrm{Al}$ addition on the microstructure and mechanical property of $\mathrm{AlxCoCrFeNi}$ highentropy alloys, Intermetallics. 26 (2012) 44-51.

[26]C.M.F. Jantzen, H. Herman, Spinodal Decomposition-Phase Diagram 
Representation and Occurrence, (1978) 127-184.

[27] W. Brandl, H.J. Grabke, D. Toma, J. Krüger, The oxidation behaviour of sprayed MCrAlY coatings, Surf. Coat. Technol. 86-87 (1996) 41-47.

[28] Y.H. Sohn, K. Vaidyanathan, M. Ronski, E.H. Jordan, M. Gell, Thermal cycling of EB-PVD/MCrAlY thermal barrier coatings: II. Evolution of photo-stimulated luminescence, Surf. Coat. Technol. 146-147 (2001) 102-109.

[29] V.K. Tolpygo, D.R. Clarke, Microstructural study of the theta-alpha transformation in alumina scales formed on nickel-aluminides, Mater. High Temp. 17 (2014) 59-70.

[30] B. Pint, The oxidation mechanism of $\theta$-A12O3 scales, Solid State Ionics. 78 (1995) 99-107.

[31] E. Hejrani, D. Sebold, W.J. Nowak, G. Mauer, D. Naumenko, R. Vaßen, W.J. Quadakkers, Isothermal and cyclic oxidation behavior of free standing MCrAlY coatings manufactured by high-velocity atmospheric plasma spraying, Surf. Coat. Technol. 313 (2017) 191-201.

[32] A. Kumar, M. Nasrallah, D.L. Douglass, The effect of yttrium and thorium on the oxidation behavior of Ni-Cr-Al alloys, Oxid. Met. 8 (1974) 227-263.

[33] T.J. Nijdam, L.P.H. Jeurgens, J.H. Chen, W.G. Sloof, On the Microstructure of the Initial Oxide Grown by Controlled Annealing and Oxidation on a NiCoCrAlY Bond Coating, Oxid. Met. 64 (2005) 355-377.

[34] T.J. Nijdam, W.G. Sloof, Effect of reactive element oxide inclusions on the growth kinetics of protective oxide scales, Acta Mater. 55 (2007) 5980-5987.

[35] D. Li, H. Guo, D. Wang, T. Zhang, S. Gong, H. Xu, Cyclic oxidation of $\beta$-NiAl with various reactive element dopants at $1200^{\circ} \mathrm{C}$, Corros. Sci. 66 (2013) 125-135.

[36] F. Gesmundo, Viani, F., Niu, Y. et al., The transition from the formation of mixed scales to the selective oxidation of the most-reactive component in the corrosion of single and two-phase binary alloys, Oxid. Met. (1993) 373.

[37] H.E. Evans, M.P. Taylor, Diffusion Cells and Chemical Failure of MCrAlY Bond Coats in Thermal-Barrier Coating Systems, Oxid. Met. 55 (2001) 17-34.

[38] H. Peng, H. Guo, J. He, S. Gong, Microscale lamellar NiCoCrAlY coating with improved oxidation resistance, Surf. Coat. Technol. 207 (2012) 110-116. 
[39] D.K. Das, M. Roy, V. Singh, S.V. Joshi, Microstructural degradation of plain and platinum aluminide coatings on superalloy CM247 during isothermal oxidation, Mater. Sci. Technol.15 (2013) 1199-1208.

[40] Z. Tang, O.N. Senkov, C.M. Parish, C. Zhang, F. Zhang, L.J. Santodonato, G. Wang, G. Zhao, F. Yang, P.K. Liaw, Tensile ductility of an AlCoCrFeNi multi-phase highentropy alloy through hot isostatic pressing (HIP) and homogenization, Mater. Sci. Eng. A. 647 (2015) 229-240.

[41] M.C. Gao, J.-W. Yeh, P.K. Liaw, Y. Zhang, High-Entropy Alloys Fundamentals and Applications, 2016.

[42] K. Ishida, T. Nishizawa, The Co-Cr (Cobalt-Chromium) system, Bulletin of Alloy Phase Diagrams, 11 (1990) 357-370.

[43] V.K. Tolpygo, D.R. Clarke, Microstructural study of the theta-alpha transformation in alumina scales formed on nickel-aluminides, Mater. High Temp. 17 (2000) 59-70. [44] D. Prajitno, B. Gleeson, D.J. Young, The cyclic oxidation behaviour of $\alpha-\mathrm{Cr}+\beta-$ NiAl alloys with and without trace Zr addition, Corros. Sci. 39 (1997) 639-654.

[45] J.L. McArdle, G.L. Messing, Transformation, Microstructure Development, and Densification in alpha-Fe2O3-Seeded Boehmite-Derived Alumina,J. Am. Ceram. Soc. 76 (1993) 214-222.

[46] G. Wang, B. Gleeson, D.L. Douglass, A diffusional analysis of the oxidation of binary multiphase alloys, Oxid. Met. 35 (1991) 333-348.

[47] C. Wagner, Theoretical Analysis of the Diffusion Processes Determining the Oxidation Rate of Alloys, J. Electrochem. Soc. 99 (1952) 369-380.

[48] F.A. Golightly, The Relationship Between Oxide Grain Morphology and Growth Mechanisms for Fe-Cr-Al and Fe-Cr-Al-Y Alloys, J. Electrochem. Soc. 126 (1979) 1035.

[49] T. Boll, K.A. Unocic, B.A. Pint, A. Mårtensson, K. Stiller, Grain Boundary Chemistry and Transport Through Alumina Scales on NiAl Alloys, Oxid. Met. 88 (2017) 469-479.

[50] K.A. Unocic, B.A. Pint, Characterization of the alumina scale formed on a commercial MCrAlYHfSi coating, Surf. Coat. Technol. 205 (2010) 1178-1182. 
[51] F. Cao, B. Tryon, C.J. Torbet, T.M. Pollock, Microstructural evolution and failure characteristics of a NiCoCrAlY bond coat in "hot spot" cyclic oxidation, Acta Mater. 57 (2009) 3885-3894.

[52] J.W. Hutchinson, M.Y. He, A.G. Evans, The influence of imperfections on the nucleation and propagation of buckling driven delaminations, J. Mech. Phys. Solids. 48 (2000) 709-734.

[53] T.J. Nijdam, C. Kwakernaak, W.G. Sloof, The effects of alloy microstructure refinement on the short-term thermal oxidation of NiCoCrAlY alloys, Metall. Mater. Trans. A. 37 (2006) 683-693.

[54] D. Naumenko, V. Shemet, L. Singheiser, W.J. Quadakkers, Failure mechanisms of thermal barrier coatings on MCrAlY-type bondcoats associated with the formation of the thermally grown oxide, J. Mater. Sci. 44 (2009) 1687-1703.

[55] E. Wessel, V. Kochubey, D. Naumenko, L. Niewolak, L. Singheiser, W. Quadakkers, Effect of $\mathrm{Zr}$ addition on the microstructure of the alumina scales on FeCrAlY-alloys, Scr. Mater. 51 (2004) 987-992.

[56] G.W. Goward, Progress in coatings for gas turbine airfoils, Surf. Coat. Technol. 108-109 (1998) 73-79.

[57] D. Pan, M.W. Chen, P.K. Wright, K.J. Hemker, Evolution of a diffusion aluminide bond coat for thermal barrier coatings during thermal cycling, Acta Mater. 51 (2003) 2205-2217.

[58] A.G. Evans, D.R. Mumm, J.W. Hutchinson, G.H. Meier, F.S. Pettit, Mechanisms controlling the durability of thermal barrier coatings, Prog. Mater. Sci.46 (2001) 505553.

[59] H.X. Zhu, N.A. Fleck, A.C.F. Cocks, A.G. Evans, Numerical simulations of crack formation from pegs in thermal barrier systems with NiCoCrAlY bond coats, Mater. Sci. Eng. A. 404 (2005) 26-32.

[60] R.A. Rapp, Chemistry and electrochemistry of hot corrosion of metals, Mater. Sci. Eng. 87 (1987) 319-327.

[61] C. Leyens, B.A. Pint, I.G. Wright, Effect of composition on the oxidation and hot corrosion resistance of NiAl doped with precious metals, Surf. Coat. Technol. 133-134 
(2000) 15-22.

[62] H. Peng, H. Guo, J. He, S. Gong, Cyclic oxidation and diffusion barrier behaviors of oxides dispersed NiCoCrAlY coatings, J. Alloys Compd. 502 (2010) 411-416.

[63] O. Knotek, E. Lugscheider, F. Löffler, W. Beele, Diffusion barrier coatings with active bonding, designed for gas turbine blades, Surf. Coat. Technol. 68-69 (1994) 2226.

[64] W.S. Walston, J.C. Schaeffer, W.H. Murphy, A new type of microstructural instability in superalloys-SRZ, Superalloys 1996 (1996) 9-18.

[65] R.C. Reed, The superalloys: fundamentals and applications, Cambridge university press, Cambridge university press, 2008.

[66] J. Lu, H. Zhang, Y. Chen, X. Zhao, F. Guo, P. Xiao, Effect of microstructure of a NiCoCrAlY coating fabricated by high-velocity air fuel on the isothermal oxidation, Corros. Sci. 159 (2019) 108126.

[67] Y.H. Jo, W.-M. Choi, S.S. Sohn, H.S. Kim, B.-J. Lee, S. Lee, Role of brittle sigma phase in cryogenic-temperature-strength improvement of non-equi-atomic Fe-rich VCrMnFeCoNi high entropy alloys, Mater. Sci. Eng. A. 724 (2018) 403-410. 